\title{
Preclinical Characteristics of the Irreversible Pan-HER Kinase Inhibitor Neratinib Compared with Lapatinib: Implications for the Treatment of HER2-Positive and HER2-Mutated Breast Cancer
}

\author{
Denis M. Collins ${ }^{1, *}$, Neil T. Conlon ${ }^{1}{ }^{(}$, Srinivasaraghavan Kannan ${ }^{2}$, Chandra S. Verma ${ }^{2,3,4}$, \\ Lisa D. Eli ${ }^{5}$, Alshad S. Lalani ${ }^{5}$ D and John Crown ${ }^{1,6}$ \\ 1 National Institute for Cellular Biotechnology, Dublin City University, Glasnevin, 9 Dublin, Ireland; \\ neil.conlon@dcu.ie (N.T.C.); john.crown@ccrt.ie (J.C.) \\ 2 Bioinformatics Institute, A*STAR (Agency for Science, Technology and Research), 30 Biopolis Street, \#07-01 \\ Matrix, Singapore 138671, Singapore; raghavk@bii.a-star.edu.sg (S.K.); chandra@bii.a-star.edu.sg (C.S.V.) \\ 3 Department of Biological Sciences, National University of Singapore, 14 Science Drive 4, \\ Singapore 117543, Singapore \\ 4 School of Biological Sciences, Nanyang Technological University, 50 Nanyang Drive, \\ Singapore 637551, Singapore \\ 5 Puma Biotechnology, Inc., 10880 Wilshire Blvd., Suite 2150, Los Angeles, CA 90024, USA; \\ leli@pumabiotechnology.com (L.D.E.); ALalani@pumabiotechnology.com (A.S.L.) \\ 6 Department of Medical Oncology, St Vincent's University Hospital, 4 Dublin, Ireland \\ * Correspondence: denis.collins@dcu.ie; Tel.: +353-1-700-5647; Fax: +353-1-700-5484
}

Received: 29 March 2019; Accepted: 17 May 2019; Published: 28 May 2019

\begin{abstract}
An estimated 15-20\% of breast cancers overexpress human epidermal growth factor receptor 2 (HER2/ERBB2/neu). Two small-molecule tyrosine kinase inhibitors (TKIs), lapatinib and neratinib, have been approved for the treatment of HER2-positive (HER2+) breast cancer. Lapatinib, a reversible epidermal growth factor receptor (EGFR/ERBB1/HER1) and HER2 TKI, is used for the treatment of advanced HER2+ breast cancer in combination with capecitabine, in combination with trastuzumab in patients with hormone receptor-negative metastatic breast cancer, and in combination with an aromatase inhibitor for the first-line treatment of HER2+ breast cancer. Neratinib, a next-generation, irreversible pan-HER TKI, is used in the US for extended adjuvant treatment of adult patients with early-stage HER2+ breast cancer following 1 year of trastuzumab. In Europe, neratinib is used in the extended adjuvant treatment of adult patients with early-stage hormone receptor-positive HER2+ breast cancer who are less than 1 year from the completion of prior adjuvant trastuzumab-based therapy. Preclinical studies have shown that these agents have distinct properties that may impact their clinical activity. This review describes the preclinical characterization of lapatinib and neratinib, with a focus on the differences between these two agents that may have implications for patient management.
\end{abstract}

Keywords: tyrosine kinase inhibitors; lapatinib; neratinib; HER2; breast cancer

\section{Introduction}

Five human epidermal growth factor receptor 2 (HER2/ERBB2/neu)-targeted therapies are currently approved by the Food and Drug Administration (FDA) for the treatment of HER2-positive (HER2+) breast cancers: trastuzumab, pertuzumab, trastuzumab emtansine (T-DM1), lapatinib, and neratinib [1]. These can be divided into three categories: anti-HER2 monoclonal antibodies (trastuzumab and pertuzumab), antibody-drug conjugate (T-DM1), and small-molecule pan-HER tyrosine kinase inhibitors (TKIs; lapatinib and neratinib). A number of other HER-directed TKIs are currently 
in development, including tucatinib [2], poziotinib [3], and pyrotinib [4]. This review focuses on preclinical findings regarding lapatinib and neratinib, the two approved small-molecule pan-HER TKIs, in order to provide an in-depth and comprehensive review of preclinical data. Clinical trials involving lapatinib and neratinib have been reviewed elsewhere $[5,6]$ and are not covered in this review.

Despite their similarities, multiple distinguishing characteristics between lapatinib and neratinib have been reported (Table 1). The two most striking are (1) the nature of target binding: lapatinib binds reversibly whereas neratinib binds irreversibly, and (2) differential affinities for epidermal growth factor receptor (EGFR/HER1/ERBB1), HER2, and HER4 (ERBB4). Additional differentiators include kinome profiles, in vitro cytotoxicities, effects on HER-family dimerization, effects on HER2 endocytosis, inhibition of mutant EGFR, HER2, or HER4, and resistance mechanisms.

Table 1. Comparison of lapatinib and neratinib.

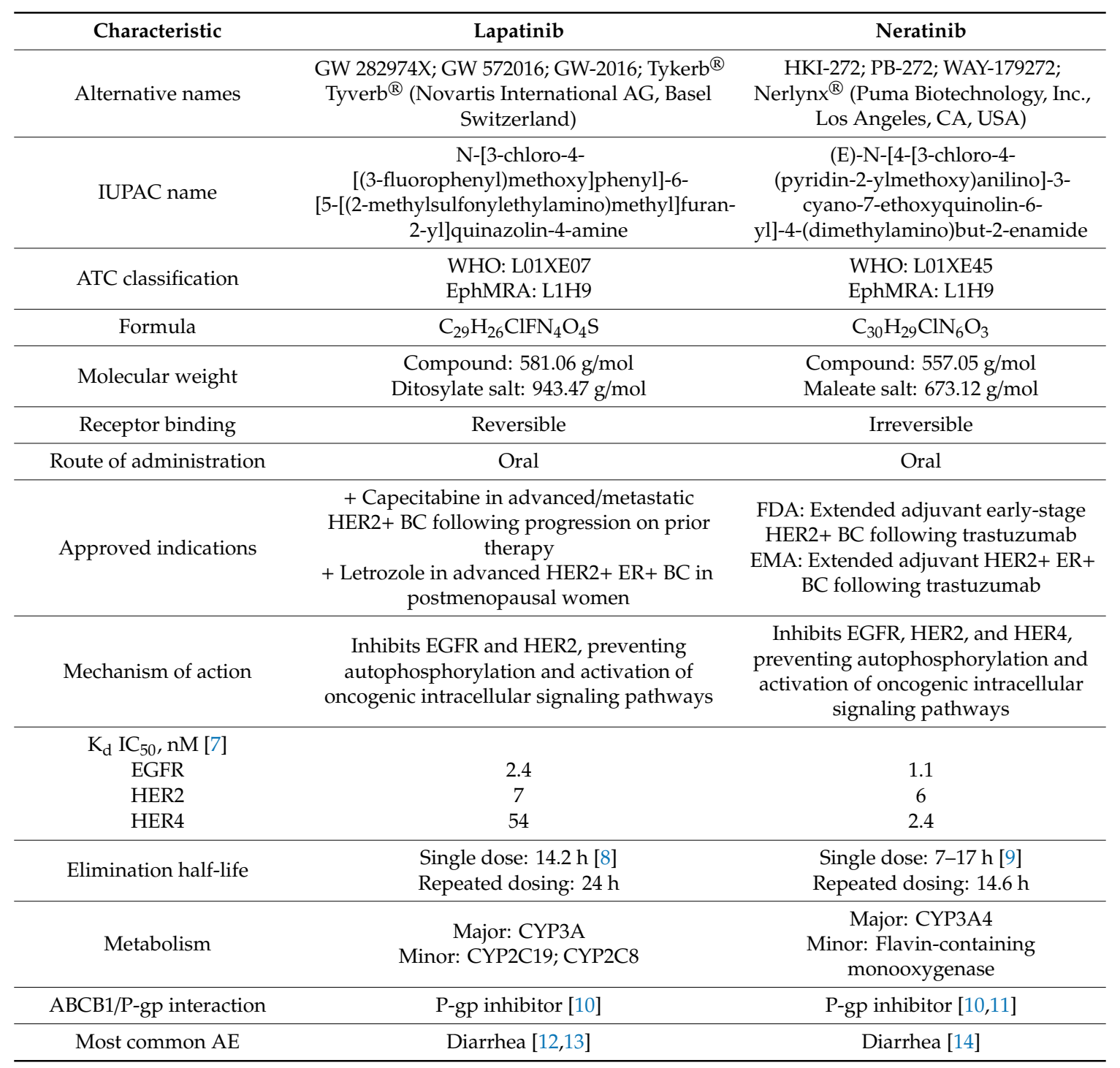

ABCB1, ATP-binding cassette sub-family B member 1; AE, adverse event; ATC, Anatomical Therapeutic Chemical; BC, breast cancer; CYP, cytochrome P450; EGFR, epidermal growth factor receptor; EMA, European Medicines Agency; EphMRA, European Pharmaceutical Market Research Association; ER, estrogen receptor; FDA, Food and Drug Administration; HER, human epidermal growth factor receptor; $\mathrm{IC}_{50}$, half maximal inhibitory concentration; $\mathrm{K}_{\mathrm{d}}$, equilibrium dissociation constant; IUPAC, International Union of Pure and Applied Chemistry; P-gp, P-glycoprotein; WHO, World Health Organization. 


\section{The HER/c-ERBB Family}

The HER family is a group of receptor tyrosine kinases (RTKs) associated with tumorigenesis [15]. The family has four members: EGFR, HER2, HER3 (ERBB3), and HER4 [15,16]. These receptors are ubiquitously expressed and are critical for normal development. HER-family RTKs have a common structural organization consisting of a ligand-binding extracellular domain (ECD), a single transmembrane segment, and an intracellular protein kinase domain with a carboxyterminal tail [17]. The ECD comprises four subdomains. Subdomain I, when bound to ligand, binds to subdomain III [18], triggering a conformational change that exposes subdomain II, the dimerization domain, allowing for receptor homo- or heterodimerization and kinase activation. Domains II and IV are involved in disulfide bond formation. Trans- or auto-phosphorylation of the C-terminal tyrosine-bearing motifs in the tail of HER family members $[15,19]$ enables recruitment of signaling molecules with Src homology 2 and phosphotyrosine-binding domains, and initiation of intracellular signaling cascades including the mitogen-activated protein kinase (MAPK) and phosphoinositide 3-kinase (PI3K) pathways [20]. These pathways subsequently activate transcription factors affecting cell survival, proliferation, motility, and differentiation $[15,17,19]$.

Eleven epidermal growth factor (EGF)-like ligands have been described (Figure 1). These ligands can be receptor-specific, e.g., EGF, transforming growth factor- $\alpha$, and epigen for EGFR, or non-specific, e.g., neuregulins for HER3 and HER4, and epiregulin for EGFR and HER4 $[15,16]$. HER2 has no known ligand. Each ligand comprises approximately 55 amino acids and shares a conserved EGF-like pattern of three disulfide bonds and a loop-rich structure [17,19,21]. Ten HER-family homo- or heterodimer combinations are possible; however, HER2 is the preferred dimerization partner as it exists in an open conformation similar to a ligand-activated state [15,22]. HER2-containing dimers have a lower dissociation rate and result in greater signal transduction compared with other dimers [23]. 


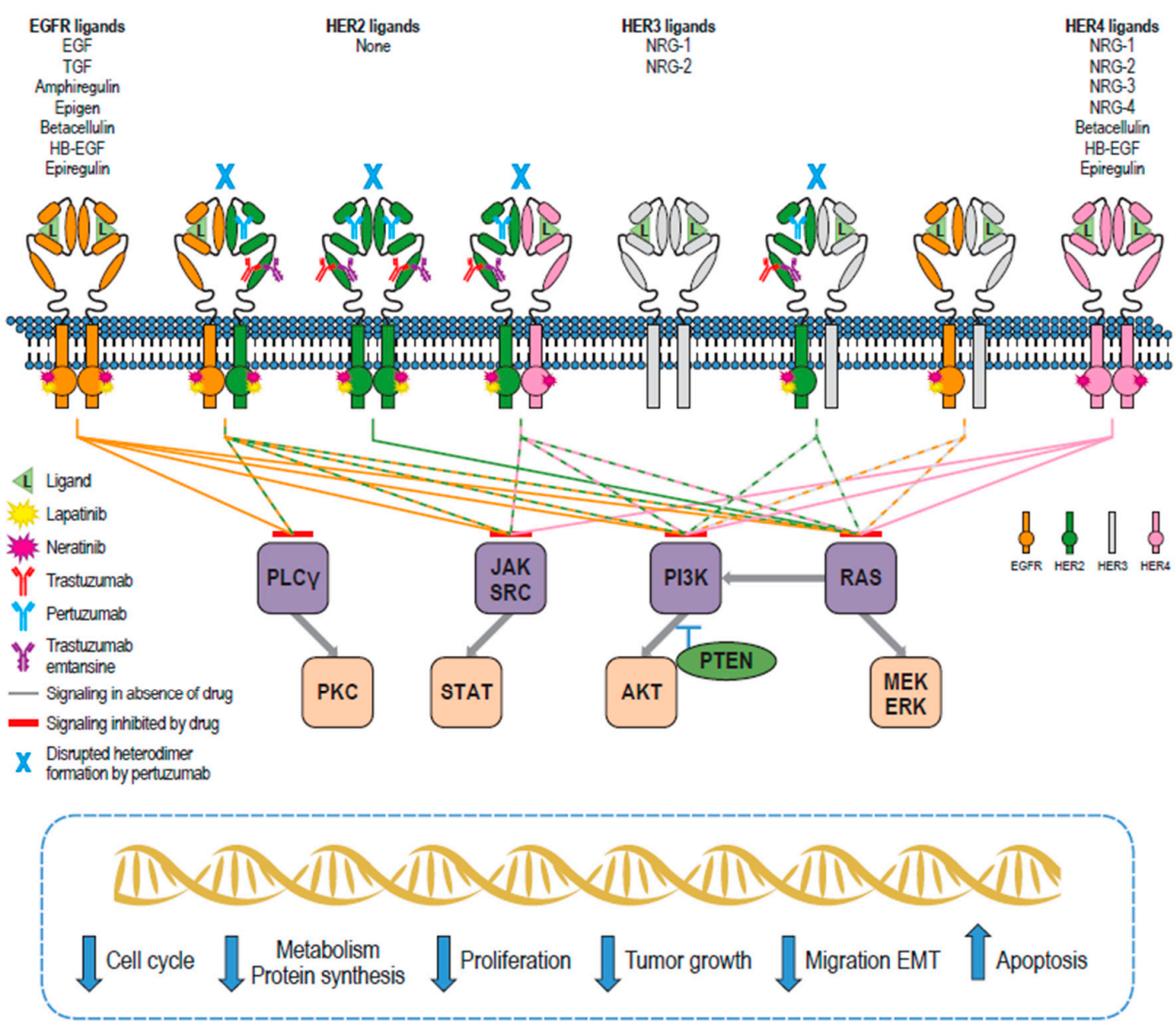

Figure 1. Schematic representation of members of the human epidermal growth factor receptor (HER) family, their natural ligands, interaction with the HER2-targeted therapies trastuzumab, pertuzumab, trastuzumab emtansine (T-DM1), lapatinib, and neratinib, and the downstream consequences of these interactions. Circles on EGFR, HER2, and HER4 represent the active kinase domain; the kinase domain on HER3 is inactive. Ligand binding initiates homo- or heterodimerization of HER family members, leading to intracellular signaling cascades that are dependent on the dimers formed (e.g., PI3K/AKT and MAPK [Ras/MEK/extracellular signal-regulated kinase (ERK)]). HER-family signaling affects multiple cell processes including cell cycle, metabolism/protein synthesis, proliferation, migration, epithelial-mesenchymal transition (EMT), and apoptosis. Trastuzumab inhibits HER2 signaling and can engage in antibody-dependent cell-mediated cytotoxicity (ADCC). Pertuzumab can also mediate ADCC and inhibits HER2 dimer formation, abrogating HER2 intracellular signaling. The trastuzumab-based antibody-drug conjugate T-DM1 maintains the functions of trastuzumab but also delivers a cytotoxic payload (emtansine) on internalization of the receptor/T-DM1 complex. Lapatinib and neratinib are small-molecule tyrosine kinase inhibitors targeting the cytoplasmic ATPase domain of HER family members. This figure is adapted from publications by Roskoski et al. [15], Segovia-Mendoza et al. [24], Kourie et al. [25], Appert-Collin et al. [26] and references cited therein; further detail can be found within those publications. Signaling pathway interactions adapted from the KEGG pathway database. AKT, protein kinase B; EGF, epidermal growth factor; EGFR, epidermal growth factor receptor; ERK, extracellular signal-regulated kinase; HB-EGF, heparin-binding EGF-like growth factor; JAK, Janus kinase; MEK, mitogen-activated protein kinase kinase; NRG, neuregulin; PI3K, phosphoinositide 3-kinase; PKC, protein kinase C; PLC $\gamma$, phospholipase C- $\gamma$; PTEN, phosphatase and tensin homolog; STAT, signal transducer and activator of transcription; TGF, transforming growth factor. 


\subsection{HER2 Overexpression}

HER2 overexpression is found in $15-20 \%$ breast cancers [27]. For other malignancies, Yan et al. reported HER2 overexpression in $4.7 \%, 11.3 \%, 12.4 \%$, and $9.8 \%$ of gastric, esophageal, bladder, and gallbladder cancers, respectively, and in $6.3 \%$ of cholangiocarcinomas [28]. The development of trastuzumab, the first clinically approved HER2-targeted agent, revolutionized outcomes for patients with HER2+ breast cancer [29,30]. Before the advent of trastuzumab, HER2+ breast cancer was considered the clinical subtype with the worst prognosis. Multiple HER2-targeting agents have since been developed, including antibody therapies such as pertuzumab, and small-molecule TKIs, such as lapatinib and neratinib, the only two TKIs approved for treatment of HER2+ breast cancer.

\subsection{HER2 Mutation}

Point mutations in genes for all four HER family members have been reported in a variety of cancers as reviewed in the COSMIC database (https://cancer.sanger.ac.uk/cosmic). Activating HER2 mutations tend to occur in the absence of HER2 amplification and their presence may represent a novel patient population potentially served by treatment with HER2-directed agents [6].

\section{Lapatinib and Neratinib: HER-Targeting Small-Molecule TKIs}

Small molecules, such as lapatinib and neratinib, have a number of inherently advantageous characteristics over monoclonal antibody therapies, including the ability to target multiple kinase family members simultaneously, to act directly at the site of intracellular signaling, and potentially to cross the blood-brain barrier [31]. In addition, as these TKIs bind intracellularly, they can inhibit p95HER2, the highly active, truncated form of HER2 that lacks most of the ECD, which trastuzumab and other ECD-directed antibody therapies cannot [2,32]. The similarities of and differences between lapatinib and neratinib are discussed below and summarized in Table 1.

\subsection{Lapatinib: A Reversible TKI}

Lapatinib (Tykerb ${ }^{\circledR}$; Tyverb ${ }^{\circledR}$; Novartis International AG, Basel, Switzerland) is a reversible TKI of EGFR and HER2. Lapatinib was approved by the FDA in 2007 and is indicated for use with capecitabine in patients with metastatic HER2+ breast cancer whose disease progressed on trastuzumab [8,33]. Lapatinib was approved in 2010 for use with letrozole in the treatment of patients with HER2+, estrogen receptor-positive (ER+) breast cancer [34]. Lapatinib was granted marketing authorization by the European Commission in 2008, and is indicated for use in combination with: capecitabine for patients with advanced or metastatic disease with progression following prior therapy, which must have included anthracyclines and taxanes, and therapy with trastuzumab in the metastatic setting; trastuzumab in patients with hormone receptor-negative metastatic breast cancer that progressed on prior trastuzumab in combination with chemotherapy; and an aromatase inhibitor for postmenopausal women with hormone receptor-positive metastatic disease, not currently intended for chemotherapy [35].

In 2001, Rusnak et al. described the activity of GW2016 (GW572016; lapatinib; Figure 2A) in preclinical models [36]. In vitro kinase assays revealed half maximal inhibitory concentration $\left(\mathrm{IC}_{50}\right)$ values against purified EGFR and HER2 of 10.8 and $9.2 \mathrm{nM}$, respectively. Proliferation $\mathrm{IC}_{50}$ values were $<160 \mathrm{nM}$ in tumor cell line models of EGFR and HER2 overexpression, 100-fold less than observed with cell line models of normal tissue. Cytotoxicity as opposed to growth arrest was confirmed using outgrowth and bromodeoxyuridine-incorporation assays, along with propidium iodide staining in head and neck (HN5) and HER2+ breast cancer (BT474) cell line models. Lapatinib displayed concentration-dependent growth inhibition of tumor xenografts using these same cell line models in vivo [36]. When bound to HER2, lapatinib inhibits both PI3K/protein kinase B (AKT) and MAPK signaling pathways [37]. MAPK signaling inhibition leads to increased expression of BCL2 interacting mediator of cell death (BIM), which results in apoptosis. Lapatinib can also induce apoptosis 
via decreasing levels of survivin and increasing levels of myeloid cell leukemia-1 (MCL-1) [38-41]. Lapatinib also induces stabilization and accumulation of HER2 on the cell surface, which may allow for greater trastuzumab-induced antibody-dependent cell-mediated cytotoxicity (ADCC) (see Section 4.6 for more detail) [42].

A<smiles>CS(=O)(=O)CCNCc1ccc(-c2ccc3ncnc(Nc4ccc(OCc5cccc(F)c5)c(Cl)c4)c3c2)o1</smiles>

B

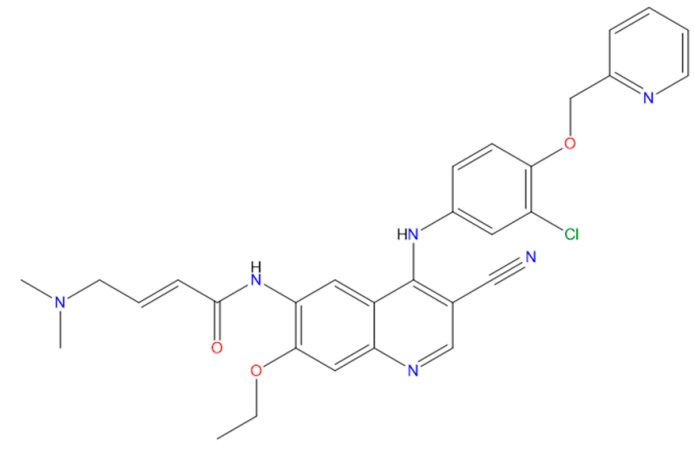

D

C

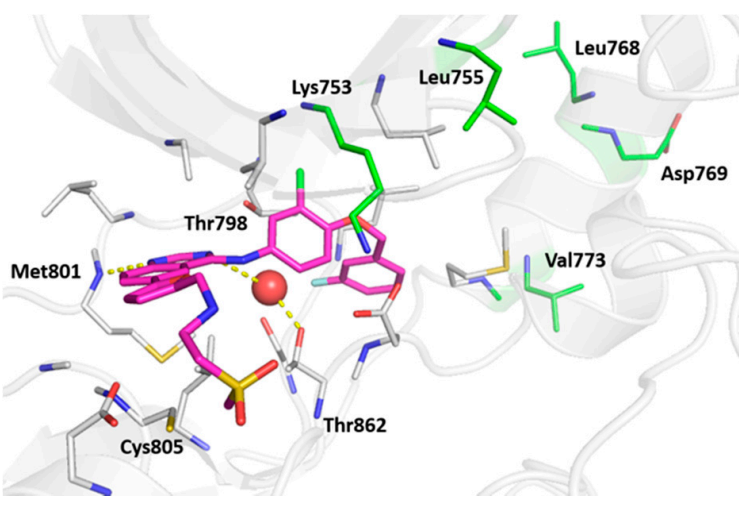

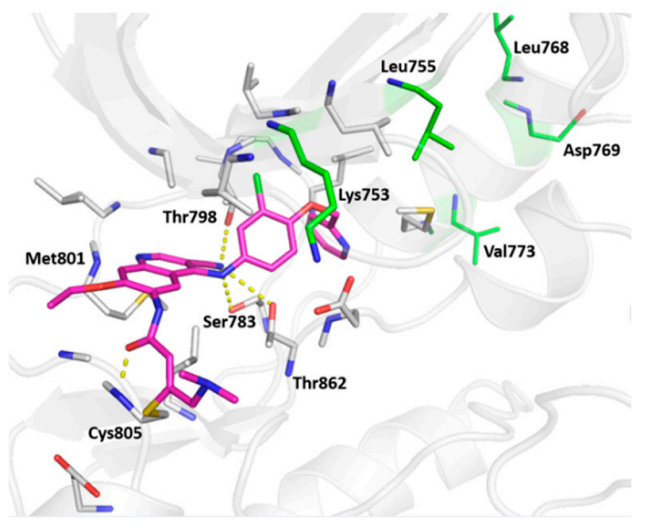

Figure 2. Chemical structures of (A) lapatinib and (B) neratinib. Modeled structures of the complexes between (C) HER2 and lapatinib and (D) HER2 and neratinib. The crystal structure of the HER2 kinase domain in its inactive form (PDB ID: 3PP0) was taken and lapatinib (guided by the crystal structure of the complex between lapatinib and HER4, PDB ID 3BBT) and separately neratinib (guided by the crystal structure of the complex of neratinib and EGFR, PDB ID 2JIV) were modeled into the binding pocket. Lapatinib and neratinib are shown as colored sticks, with carbon atoms in magenta, nitrogen atoms in blue, oxygen atoms in red, sulfur atoms in yellow, chlorine atoms in green, and fluorine atoms in cyan. Lapatinib is bound non-covalently, whereas neratinib is covalently attached to the sulfur of Cys805. All interacting residues are highlighted as thin sticks (gray carbon) and all interactions are highlighted as dotted lines (yellow). HER2 mutations that are resistant to lapatinib are highlighted (green carbon, stick representation). A key water molecule (red sphere, Panel C) that mediates interactions between lapatinib and HER2 is shown. Hydrogen bonds made by the ligands are shown as thick yellow dashes. Lapatinib is engaged in hydrophobic interactions, one hydrogen bond with the backbone amide of Met801 and one water-mediated hydrogen bond with the side-chain hydroxyl of Thr862. Neratinib is engaged in hydrophobic interactions, forming a hydrogen bond with the side chain of Ser783, a hydrogen bond with the side chain of Thr862, a hydrogen bond with the backbone of Cys805, and a hydrogen bond with the side-chain hydroxyl of the gatekeeper Thr798. Modeling, docking, and optimization using molecular dynamics simulations (250 ns simulations of each complex performed in triplicate) of the complexes were performed using standard methods ([43]; in the current study we used Amber [44] version 16 and the Amber ff14SB force field [45]). HER, human epidermal growth factor receptor. 


\subsection{Neratinib: An Irreversible TKI}

Neratinib (Nerlynx ${ }^{\circledR}$; Puma Biotechnology, Inc., Los Angeles, CA, USA) is an irreversible pan-HER TKI approved by the FDA in 2017 [9]. Neratinib is indicated for the extended adjuvant treatment of adult patients with early-stage HER2-overexpressed/amplified breast cancer, following adjuvant trastuzumab-based therapy [14]. Neratinib was granted marketing authorization by the European Commission in 2018 and is indicated for extended adjuvant treatment of adult patients with early-stage hormone receptor-positive HER2-overexpressed/amplified breast cancer who are less than 1 year from the completion of prior adjuvant trastuzumab-based therapy [46].

Neratinib (compound 25o, HKI-272), an anilinoquinoline derivative of pelitinib (EKB-569; Wyeth; Figure 2B) [46], was discovered during screening of 6,7-disubstituted-4-(arylamino)quinoline-3carbonitrile derivatives [47], and was one of six novel compounds deemed to be the best candidate dual inhibitors of HER2 and EGFR, as assessed by kinase and cell-proliferation assays. Subsequent to extensive toxicological and pharmacokinetic studies $[47,48]$, neratinib was chosen for clinical evaluation.

Kinase assays revealed that neratinib inhibited HER2 and EGFR activity at nanomolar concentrations (mean $\mathrm{IC}_{50} \pm$ standard error [SE]: $59 \pm 13 \mathrm{nM}$ and $92 \pm 17 \mathrm{nM}$, respectively), without significantly affecting the activity of a panel of serine/threonine kinases, including AKT, cyclin D1/ CDK4, cyclin E/CDK2, cyclin B1/CDK1 and c-RAF, or the tyrosine kinase c-Met [48]. Neratinib has been reported to inhibit HER4 activity at a mean $\mathrm{IC}_{50}$ of $19 \mathrm{nM}$ [48]. Protein-binding dye proliferation assays in a panel of cell lines with varying EGFR and HER2 expression confirmed the selectivity of neratinib for these receptors with low nanomolar IC $_{50}$ values $(2-3 \mathrm{nM})$ for HER2-overexpressing cell lines (SKBR3, BT474, and 3T3/neu) and a slightly higher IC $_{50}$ value for the EGFR-overexpressing epidermoid carcinoma cell line A431 (mean \pm SE: $81 \pm 9 \mathrm{nM}$ ) [48]. Mean $\pm \mathrm{SE} \mathrm{IC}_{50}$ values in HER2/EGFR-negative cell lines (3T3, MDA-MB-435, and SW620) were all $\geq 690 \pm 84 \mathrm{nM}$. Neratinib inhibited ligand-dependent and -independent phosphorylated HER2 and EGFR activity and downstream MAPK and AKT signaling (Figure 1) [48]. Neratinib, which was confirmed to bind covalently based on its antiproliferative effect in a cell line model despite withdrawal of the drug, was found to have a concentration-dependent impact on cell cycle-related cyclin D1, protein 27, and retinoblastoma protein. Finally, neratinib significantly inhibited tumor growth in vivo in xenograft models overexpressing HER2 (3T3/neu and BT474) and EGFR (SKOV-3 and A431) [48]. The pharmacodynamics, pharmacokinetics, and potential therapeutic niches of neratinib have been reviewed $[25,49,50]$.

\section{Differentiating Features of Lapatinib and Neratinib}

\subsection{Impact on HER-Family Dimerization}

As well as inhibiting intracellular phosphorylation, lapatinib and neratinib have been shown to interfere with HER receptor dimerization, unlike other TKIs such as gefitinib and erlotinib [51]. Because of their structure and binding characteristics, lapatinib and neratinib bind to the inactive conformation of HER family members, restricting ligand-induced activation (Figure 2C,D) [7]. However, Claus et al. recently provided evidence from two- and three-dimensional modeling of HER2+ breast cancer that lapatinib and neuregulin synergize to enhance proliferation [52]. The authors suggested that lapatinib induces a HER2/HER3 conformation that is distinct from the canonical ligand-induced heterodimer, is dependent on the ability of HER3 to bind adenosine $5^{\prime}$-triphosphate (ATP), and is primed for activation by neuregulin. Interestingly, this synergistic effect was not observed with neratinib and neuregulin in the same model. The authors postulated that the irreversible, covalent nature of neratinib binding, as opposed to the reversible, non-covalent lapatinib binding, explains this difference. A later study by Canonici et al. provided similar results and is covered in more detail in Section 4.4 [53].

\subsection{Characterization of the Kinomes Inhibited by Lapatinib and Neratinib}

Small-molecule kinase inhibitors are designed to target the functionally and structurally conserved ATP binding site of kinases. This frequently leads to polypharmacology, or off-target sites of action. Type 
II kinase inhibitors, including neratinib and lapatinib, bind kinase domains in a DFG (Asp-Phe-Gly)-out, inactive kinase conformation, which allows them access to an allosteric binding pocket adjacent to the ATP site, conferring greater selectivity in most, but not all, cases. Type I kinase inhibitors generally bind kinases at the ATP site in their active conformation, and therefore do not have access to the allosteric binding pocket, resulting in greater selective variability [54].

Kinome inhibition experiments have demonstrated significantly different binding patterns for neratinib and lapatinib. Davis et al. screened the activity of a set of 72 known kinase inhibitors, including neratinib and lapatinib, against a panel of 442 kinase competition-binding assays representing $>80 \%$ of catalytically active human protein kinase domains [7]. Lapatinib, which is not a typical Type II inhibitor because of its unusual displacement of the $\alpha$-C helix [55], was among the most selective of the inhibitors tested (Figure 3A). Neratinib was less selective than lapatinib, targeting EGFR, HER2, and HER4, along with members of the TK and STE kinome subdomains, particularly KHS1/KHS2 (Figure 3B). Target kinases with lower binding affinities were also identified in the TKL, CMGC, AGC, CK1, and CAMK subdomains. Klaeger et al. used a chemical proteomic approach (kinobeads) and quantitative mass spectrometry to analyze the target kinome of 243 clinically relevant kinase inhibitors, including lapatinib and neratinib [56]. Their findings confirmed the results of the study by Davis et al. [7], with lapatinib proving more selective than neratinib. The Klaeger et al. data are accessible through proteomicsDB (https://www.proteomicsdb.org/\#projects/4257); the Davis et al. database can be visualized through KinMap (http://kinhub.org/index.html) using the Profiling function.

A

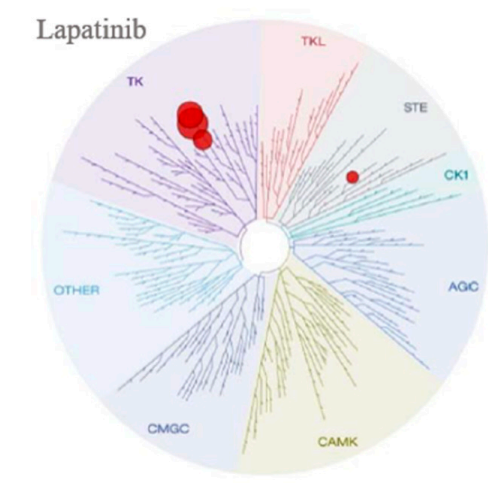

B

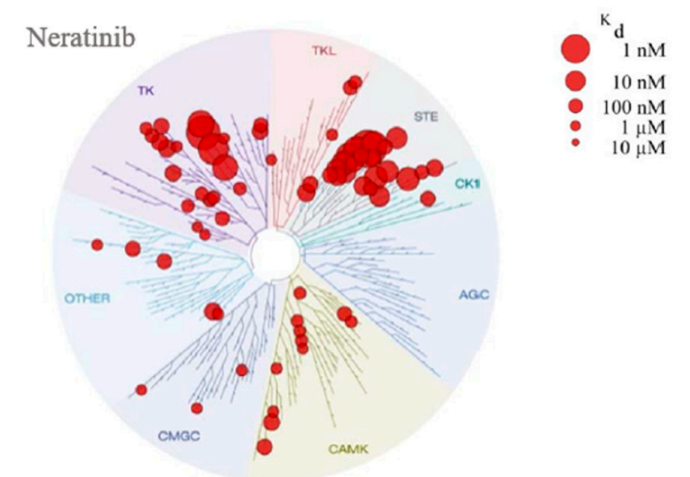

Figure 3. KINOMEscans ${ }^{\circledR}$ (Eurofins DiscoveRx, San Diego, CA, USA) of (A) lapatinib and (B) neratinib. Each red circle indicates a kinase found to bind to the drug. Larger circles indicate higher affinity interactions. Interactions with $\mathrm{K}_{\mathrm{d}}<3 \mu \mathrm{M}$ are shown. Reprinted by permission from Springer Nature: Nature Biotechnology (Comprehensive analysis of kinase inhibitor selectivity, Davis MI, et al., copyright $2011[7]) . K_{d}$, equilibrium dissociation constant.

High selectivity in a kinase inhibitor is usually advantageous for cancer subtypes driven by a particular target, as reduced off-target effects generally lead to reduced cytotoxicity; however, targeting a larger proportion of the kinome also has its advantages. Neratinib's more complete irreversible inhibition of the disease-related HER family is thought to prevent the development of resistance mediated through other HER family members [57]. Lapatinib has high affinity for EGFR and HER2 but is reversible, which leads to incomplete inhibition and reactivation of its targets [58]. Neratinib also binds with high affinity to MEK1 and MEK2, targets downstream of the HER family, potentially adding to its antiproliferative effects [59].

The off-target effects of neratinib may contribute to improved synergy with other targeted therapies and chemotherapies, such as dasatinib, which also inhibit kinases in the TK, TKL, and STE subdomains [60]. It should be noted, however, that although neratinib is a less selective inhibitor than lapatinib as visualized through inhibition of the kinome, it does not bind irreversibly off-target in the absence of the requisite cysteine residues. This distinction between affinity for its primary 
targets and the targets to which neratinib covalently binds allows for different administration and half-lives of activity for on- versus off-target effects. In addition, the measured binding affinities for neratinib kinome targets of 100-3000 nM suggest that many of the interactions may not have clinical significance as the intra-tumoral concentrations required may not be achieved with approved doses in patients $(240 \mathrm{mg}$; mean \pm standard deviation maximum plasma concentration $75.9 \pm 12.9 \mathrm{ng} / \mathrm{mL} ; 113 \pm$ $19 \mathrm{nM}$ [61].

\subsection{Mechanistic Interaction with the HER Family}

In addition to differences in their selectivity profiles, lapatinib and neratinib also vary in how they interact with HER family members. Using existing crystal structure data for EGFR-erlotinib interactions as a template, Tsou et al. built a homology model of the HER2 catalytic domain [47]. The authors proposed a mechanism for inhibition whereby the headpiece of the neratinib molecule inserts into the ATP binding pocket, allowing an electron-withdrawing group in close proximity to a double bond (a Michael acceptor) to be positioned so as to interact with a cysteine residue of EGFR that is analogous to cysteine residues in other HER family members. This arrangement leads to a covalent interaction between the $\beta$-carbon and the cysteine residues [47]. The irreversible covalent binding of neratinib to Cys-797 of EGFR overcomes resistance to the gatekeeper EGFR T790M mutation, a common resistance mechanism to erlotinib or gefitinib in L858R-mutated lung cancer $[62,63]$.

\subsection{Cytotoxicity in HER2+ and EGFR+ Cell Lines}

The cytotoxicities of lapatinib and neratinib have been widely investigated. Both agents have demonstrated in vitro and in vivo efficacy against HER2- and EGFR-amplified breast cancer cell lines, with neratinib demonstrating significantly lower $\mathrm{IC}_{50}$ values in cell line models. Neratinib was more potent than lapatinib in each cell line examined and this was the case for both ER+/HER2+ and ER-negative/HER2+ cell lines (Table 2). A caveat to $\mathrm{IC}_{50}$ comparisons is that many studies were performed under different conditions, using different assays to assess proliferation. Nonetheless, some notable differences between the agents have been observed. 
Table 2. $\mathrm{IC}_{50}$ values for lapatinib and neratinib in cell-based assays: therapy-naive and targeted therapy-resistant cell lines.

\begin{tabular}{|c|c|c|c|c|c|}
\hline \multirow{2}{*}{ Cell Line } & \multirow{2}{*}{$\begin{array}{c}\text { Breast Cancer } \\
\text { Subtype } \\
{[64-66]}\end{array}$} & \multirow{2}{*}{$\begin{array}{c}\text { Sensitivity to } \\
\text { Trastuzumab * } \\
\text { [67] }\end{array}$} & \multicolumn{2}{|c|}{$\mathrm{IC}_{50}$ Value $\pm \mathrm{SD}(\mathrm{nM})$} & \multirow{2}{*}{ Reference } \\
\hline & & & Lapatinib & Neratinib & \\
\hline \multirow[t]{4}{*}{ BT474 } & HER2+/ER+ & $S$ & 23 & 3 & [57] \\
\hline & & & $36 \pm 15.1$ & $1.9 \pm 0.46$ & {$[68,69]$} \\
\hline & & & $23.9 \pm 19.6$ & $0.84 \pm 0.11$ & {$[53]$} \\
\hline & & & $16 \pm 11^{\dagger}$ & $<5$ & [25] \\
\hline \multirow[t]{2}{*}{ EFM-192A } & HER2+/ER+ & $S$ & $20.2 \pm 0.186$ & $2.38 \pm 0.23$ & [53] \\
\hline & & & $75 \pm 2^{\dagger}$ & $<5$ & [25] \\
\hline \multirow[t]{2}{*}{ UACC-812 } & HER2+/ER+ & $S$ & $80.4 \pm 32.7$ & $4.03 \pm 0.14$ & [53] \\
\hline & & & $432 \pm 116^{+}$ & $<5$ & [25] \\
\hline MDA-MB-361 & HER2+/ER+ & S & $323.5 \pm 50.8$ & $7.36 \pm 2.65$ & [53] \\
\hline HCC1419 & HER2+/ER- & $\mathrm{R}$ & $63.1 \pm 29.7$ & $3.94 \pm 0.5$ & [53] \\
\hline \multirow[t]{2}{*}{ HCC1569 } & HER2+/ER- & $\mathrm{R}$ & $242 \pm 8.7$ & $36.24 \pm 4.85$ & [53] \\
\hline & & & $3550 \pm 715^{\dagger}$ & $<5$ & [25] \\
\hline \multirow[t]{2}{*}{ HCC1954 } & HER2+/ER- & $\mathrm{R}$ & $582 \pm 31$ & $24.73 \pm 5.42$ & [53] \\
\hline & & & $358 \pm 64^{\dagger}$ & $<5$ & [25] \\
\hline JIMT-1 & HER2+/ER- & $\mathrm{R}$ & $1416 \pm 371.9$ & $141.5 \pm 9.61$ & [53] \\
\hline \multirow[t]{3}{*}{ MDA-MB-453 } & HER2+/ER- & $\mathrm{R}$ & 260 & 110 & [57] \\
\hline & & & $6080 \pm 825$ & $820 \pm 140$ & {$[68,69]$} \\
\hline & & & $5186.3 \pm 1542.8$ & $267.23 \pm 22.52$ & {$[53]$} \\
\hline \multirow[t]{5}{*}{ SKBR3 } & HER2+/ER- & S & 15 & 3 & [57] \\
\hline & & & $80 \pm 17.3$ & $2.26 \pm 0.08$ & {$[68,69]$} \\
\hline & & & $25.9 \pm 2.9$ & $1.26 \pm 0.24$ & [53] \\
\hline & & & $54 \pm 8^{\dagger}$ & 5 & [25] \\
\hline & & & 89 & 2.1 & [70] \\
\hline SUM-190 & HER2+/ER- & $\mathrm{D}$ & $38 \pm 3^{+}$ & $10 \pm 0.0^{+}$ & [25] \\
\hline SUM-225 & HER2+/ER- & $\mathrm{R}$ & $89 \pm 52^{+}$ & $10 \pm 0.0^{\dagger}$ & [25] \\
\hline \multirow[t]{2}{*}{ UACC-732 } & HER2+/ER- & $\mathrm{R}$ & $3180 \pm 939$ & $132.23 \pm 19.66$ & [53] \\
\hline & & & $2629 \pm 480^{+}$ & $650 \pm 370^{+}$ & [25] \\
\hline UACC-893 & HER2+/ER- & $\mathrm{R}$ & $1211 \pm 251^{\dagger}$ & $<5$ & [25] \\
\hline MCF7 & $\mathrm{ER}+$ & & 2660 & 350 & [57] \\
\hline T47D & ER+ & & 2870 & 890 & [57] \\
\hline HCC1937 & TNBC & & 6000 & 750 & [70] \\
\hline SUM-229PE & TNBC & & 350 & 14 & [70] \\
\hline MDA-MB-231 & TNBC & & 9290 & 1350 & [57] \\
\hline MDA-MB-468 & $\begin{array}{c}\text { TNBC } \\
\text { (EGFR-amplified) }\end{array}$ & & 1730 & 36 & [57] \\
\hline \multicolumn{6}{|c|}{ Resistant cell line models } \\
\hline HCC1954-Par & HER2+/ER- & $\mathrm{R}$ & 273 & 49 & [71] \\
\hline HCC1954-NR & HER2+/ER- & & 2700 & 325 & [71] \\
\hline EFM192A-Par & HER2+/ER+ & $S$ & 50 & 6.8 & [71] \\
\hline EFM192A-NR & HER2+/ER+ & & 7970 & 46.7 & [71] \\
\hline BT474/AZ-P & HER2+/ER+ & $S$ & 80 & 0.24 & [72] \\
\hline BT474-LR & HER2+/ER+ & & 3000 & 8 & [72] \\
\hline BT474/ATCC-P & HER2+/ER+ & S & 80 & 0.72 & [72] \\
\hline BT474-LTR & HER2+/ER+ & & 3800 & 16 & {$[72]$} \\
\hline
\end{tabular}

* Sensitivity to trastuzumab based on 2- and 3-dimensional assays as determined by $\mathrm{O}^{\prime}$ Brien et al. [67]. ${ }^{+}$Standard error. +, positive; -, negative; D, distinct (resistant in 2-dimensional assay, sensitive in 3-dimensional assay); EGFR, epidermal growth factor receptor; ER, estrogen receptor; HER, human epidermal growth factor receptor; $\mathrm{IC}_{50}$, half maximal inhibitory concentration; LR, lapatinib-resistant; LTR, lapatinib- and trastuzumab-resistant; NR, neratinib-resistant; R, resistant; $\mathrm{S}$, sensitive; SD, standard deviation; TNBC, triple-negative breast cancer.

Canonici et al. examined sensitivity to neratinib in a panel of 36 breast cancer cell lines including 12 HER2+ cell lines [73]. All HER2+ cell lines examined were more sensitive to neratinib than lapatinib based on previously published $\mathrm{IC}_{50}$ values for lapatinib in the same cell lines [67]. Neratinib sensitivity 
correlated with total and phosphorylated HER2 levels in the HER2-positive breast cancer panel. Similarly, Konecny et al. showed that total HER2 levels, and not EGFR levels, were predictive of in vitro response [37]. In a panel of trastuzumab-sensitive cell lines, trastuzumab plus neratinib was more potent than either drug alone [73]. In contrast, in a panel of trastuzumab-resistant HER2+ cell lines sensitive to neratinib, addition of trastuzumab did not provide added benefit.

Neratinib was compared with lapatinib and with afatinib, another irreversible pan-HER TKI, in a panel of 11 HER2+ breast cancer cell lines [53]. Neratinib was more potent than lapatinib in all 11 cell lines in this study and was more potent than afatinib in nine. Each of the cell lines was classified as sensitive or resistant to each of the TKIs: three displayed innate resistance to all three TKIs (JIMT-1, MDA-MB-453, and UACC-732). Combination proliferation assays were carried out in three of the HER2+ breast cancer cell lines that were: (1) sensitive to trastuzumab/lapatinib (SKBR3); (2) resistant to the combination of trastuzumab/lapatinib/neratinib/afatinib (MDA-MB-453); and (3) sensitive to lapatinib/resistant to trastuzumab (HCC1569). Addition of any of the three TKIs improved response to trastuzumab in SKBR3, but addition of pertuzumab did not. Combination with a TKI did not enhance response to trastuzumab in the MDA-MB-453 or HCC1569 cell lines but the triplet of trastuzumab/pertuzumab/neratinib showed the strongest antiproliferative effect. Addition of the ligands amphiregulin and heregulin altered responses; in the presence of either ligand, increasing the concentration of trastuzumab, pertuzumab, or neratinib alone had no effect, but growth inhibition was significant when all three inhibitors were combined.

A comprehensive study by Stanley et al. examined a panel of breast cancer cell lines for HER-family expression and sensitivity to reversible and irreversible HER-family inhibitors alone or in combination with other targeted kinases and chemotherapeutic agents [57]. In this panel, which included the SKBR3, BT474, and MDA-MB-453 HER2+ cell lines and the MDA-MB-468 EGFR+ cell line, IC 50 values were lower for neratinib than lapatinib for all cell lines examined. Neratinib $\mathrm{IC}_{50}$ values were equivalent to or lower than those of afatinib. The authors found no statistically significant relationship between EGFR, HER2, or HER3 expression and response to lapatinib or neratinib. Analysis of the phosphorylation of HER family members in the SKBR3 cell line, with or without the HER-family ligands EGF, heparin-binding EGF, and neuregulin, found that irreversible HER-family TKIs were more effective than reversible TKIs at inhibiting phosphorylation of HER-family receptors and downstream signaling molecules (AKT/MAPK).

In summary, preclinical assessment of cytotoxicity suggests several differences between neratinib and lapatinib. Neratinib is a more potent inhibitor of proliferation and downstream signaling pathways than lapatinib or afatinib in cell line models of HER2+ breast cancer and can potentiate the effects of trastuzumab in trastuzumab-sensitive HER2+ breast cancer cell lines. Cell line models with innate or acquired trastuzumab resistance are sensitive to neratinib, whereas neratinib-resistant cell line models are cross-resistant to trastuzumab, lapatinib, and afatinib. Incomplete inhibition of HER family members by lapatinib may be a determining factor that allows resistance to develop through activation of EGFR/HER3 and HER4. The addition of a TKI to trastuzumab is beneficial, with both lapatinib and neratinib improving response to trastuzumab in trastuzumab-sensitive HER2+ cells; the addition of pertuzumab does not enhance this effect. The triple combination of trastuzumab, pertuzumab, and neratinib was more effective than the lapatinib triplet in innately HER2-targeted therapy-resistant cell line models.

\subsection{Cytotoxicity in HER2-Mutant Cell Lines}

A recently identified patient population that may benefit from HER2 inhibitors are those whose tumors harbor activating HER2 mutations, even in the absence of gene amplification. Multiple studies have reported that oncogenic HER2 mutations occur primarily in the kinase domain of HER2 [74,75]. Analysis of eight breast cancer genome-sequencing studies identified 13 HER2 mutations from 25 patients with non-HER2-amplified breast cancer (Table 3). Functional characterization classified seven of the 13 mutations as HER2 activating, based on increased EGFR and HER3 phosphorylation compared 
with wild-type HER2 [75]. In mouse xenograft studies, NIH3T3 cells transduced with three mutations (V777L, D769H and G309A) displayed more rapid tumor growth than HER2 wild-type controls [75].

Table 3. $\mathrm{IC}_{50}$ values for neratinib and lapatinib in cell-based assays: cell lines with HER2 mutations.

\begin{tabular}{|c|c|c|c|c|}
\hline \multirow{2}{*}{$\begin{array}{l}\text { Study and Cell } \\
\text { Line }\end{array}$} & \multirow{2}{*}{ HER2 Mutation } & \multirow{2}{*}{$\begin{array}{c}\text { Breast Cancer } \\
\text { Subtype [64-66] }\end{array}$} & \multicolumn{2}{|c|}{$\mathrm{IC}_{50} \pm \mathrm{SD}(\mathrm{nM})$} \\
\hline & & & Neratinib & Lapatinib \\
\hline \multicolumn{5}{|l|}{ Bose et al. [75] } \\
\hline \multirow{7}{*}{ MCF10A } & HER2 WT & \multirow[t]{7}{*}{$\begin{array}{l}\text { Non-tumorigenic, } \\
\text { epithelial breast }\end{array}$} & $<2$ & $400 \pm 60$ \\
\hline & G309A & & $<2$ & $470 \pm 50$ \\
\hline & V777L & & $<2$ & $1040 \pm 570$ \\
\hline & $\mathrm{D} 769 \mathrm{H}$ & & $<2$ & $980 \pm 950$ \\
\hline & V842I & & $<2$ & $650 \pm 210$ \\
\hline & del.755-759 & & $2.1 \pm 0.2$ & $660 \pm 90$ \\
\hline & L755S & & $15.6 \pm 6$ & $>10,000$ \\
\hline BT474 & & HER2+/ER+ & $<2$ & $32 \pm 2$ \\
\hline MCF7 & & ER+ & $>3000$ & $>10,000$ \\
\hline \multicolumn{5}{|l|}{ Zuo et al. [76] } \\
\hline \multirow{8}{*}{ MCF10A } & HER2 WT & \multirow[t]{8}{*}{$\begin{array}{l}\text { Non-tumorigenic, } \\
\text { epithelial breast }\end{array}$} & $<2$ & $480 \pm 50$ \\
\hline & K75E & & $32 \pm 8$ & $>10,000$ \\
\hline & L768S & & $<2$ & $1050 \pm 480$ \\
\hline & V773L & & $<2$ & $960 \pm 380$ \\
\hline & R647K & & $<2$ & $650 \pm 370$ \\
\hline & $\mathrm{I} 655 \mathrm{~V}$ & & $<2$ & $520 \pm 420$ \\
\hline & K676R & & $<2$ & $385 \pm 270$ \\
\hline & Q680R & & $<2$ & $550 \pm 190$ \\
\hline \multirow{9}{*}{ BT474 } & Parental & \multirow[t]{9}{*}{ HER2+/ER+ } & $<2$ & $72 \pm 24$ \\
\hline & HER2 WT & & $<2$ & $109 \pm 36$ \\
\hline & K75E & & $40 \pm 8$ & $1240 \pm 460$ \\
\hline & L768S & & $<2$ & $286 \pm 110$ \\
\hline & V773L & & $<2$ & $218 \pm 85$ \\
\hline & R647K & & $<2$ & $86 \pm 40$ \\
\hline & $\mathrm{I} 655 \mathrm{~V}$ & & $<2$ & $120 \pm 52$ \\
\hline & K676R & & $<2$ & $64 \pm 36$ \\
\hline & Q680R & & $<2$ & $78 \pm 5$ \\
\hline \multirow{8}{*}{ MDA-MB-231 } & HER2 WT & \multirow[t]{8}{*}{ TNBC } & $410 \pm 140$ & $3620 \pm 860$ \\
\hline & K75E & & $889 \pm 215$ & $>10,000$ \\
\hline & L768S & & $590 \pm 165$ & $4980 \pm 1110$ \\
\hline & V773L & & $780 \pm 184$ & $4980 \pm 785$ \\
\hline & R647K & & $472 \pm 106$ & $3578 \pm 759$ \\
\hline & $\mathrm{I} 655 \mathrm{~V}$ & & $508 \pm 108$ & $3496 \pm 808$ \\
\hline & K676R & & $537 \pm 124$ & $3730 \pm 960$ \\
\hline & Q680R & & $496 \pm 98$ & $3778 \pm 845$ \\
\hline MCF7 & Parental & ER+ & $>3000$ & $>10,000$ \\
\hline \multicolumn{5}{|l|}{ Cocco et al. [5] } \\
\hline BT474 & L755S & HER2+/ER+ & 6.7 & 583.8 \\
\hline SKBR3 & L755S & HER2+/ER- & 10.2 & 1424 \\
\hline
\end{tabular}

ER, estrogen receptor; HER, human epidermal growth factor receptor; $\mathrm{IC}_{50}$, half maximal inhibitory concentration; $\mathrm{SD}$, standard deviation; TNBC, triple-negative breast cancer; WT, wild type.

An understanding of which HER2 mutations are responsive to which HER2 inhibitors is critical. For example, the HER2 L755S mutation is known to be associated with lapatinib resistance. When 
retrovirally induced in the MCF-10A non-transformed breast epithelial cell line, HER2 L755S mediated resistance to lapatinib - but not neratinib—as determined by inhibition of both cell growth and HER2 phosphorylation [75]. A further study of HER2 L755S reported that this mutation arose independently in two resistant cell line models derived from BT474: the lapatinib-resistant BT-474-AZ/LR and the lapatinib- and trastuzumab-resistant BT474/ATCC-LTR cell lines [72]. Small interfering RNA knockdown of HER2 L755S reversed this resistance, whereas ectopic expression of HER2 L755S conferred resistance to lapatinib in treatment-naive BT474, SKBR3, and AU565 cell lines. Neratinib also overcame resistance to lapatinib and lapatinib/trastuzumab in two BT474 cell line models harboring the L755S mutations [72]. Further, the non-small cell lung cancer-associated HER2 L755P mutation also mediated lapatinib resistance [77]. Neratinib was more potent by orders of magnitude than lapatinib in six of the HER2-mutant MCF10A and HER2 wild-type-transduced MCF10A cell lines [75]. In 3-dimensional Matrigel ${ }^{\circledR}$ (BD Biosciences, San Jose, CA, USA) assays, the HER2 mutation P780_Y781insGSP conferred resistance to trastuzumab and lapatinib, but not to neratinib. A patient with HER2 L869R-mutant breast cancer initially achieved a partial response following neratinib treatment, followed by disease progression with acquisition of a secondary 'gatekeeper' HER2 mutation, T798I [78]. In vitro analysis showed that although neratinib was ineffective against this dual HER2 mutant, afatinib and the osimertinib metabolite AZ5104 could inhibit HER2 phosphorylation.

Others have suggested that cancers harboring exon 20 mutations that mediate resistance to lapatinib/trastuzumab may be sensitive to neratinib treatment [79]. Koga et al. reported lower sensitivity index values for neratinib than lapatinib in lung adenocarcinomas harboring the HER2 exon 20 insertion mutations A775_G776insYVMA, G776delinsVC, and P780_Y781insGSP [80]. In the SUMMIT trial, $50 \%$ of patients in the breast cancer cohort in whom exon 20 insertions were observed responded to treatment with neratinib, unlike the non-small cell lung cancer cohort, in which response to neratinib was limited in patients with such mutations [81].

Co-occurrence of HER2 amplification and mutation has also been documented. Screening of 22 HER2 exons in 1248 primary breast cancers and 18 matched metastatic samples identified HER2 mutation in $2.24 \%$ of tumors ( 28 of 1248 ) [76]. In that study, mutation rates were similar in HER2+ and HER2-negative tumors: among HER2+ tumors, the HER2 mutation rate was $2.31 \%$ (21 of 910) versus $2.07 \%$ (7 of 338) in HER2-negative tumors. Functional analysis of these mutations suggested that L755S and K753E mutations were associated with resistance to lapatinib and trastuzumab but not neratinib. In NIH3T3 cells, those bearing the HER2 L768S and V773L mutations formed tumors more rapidly than those with wild-type HER2. MCF10A, BT474, and MDA-MB-231 cells bearing the K753E mutation were resistant to lapatinib but not neratinib, and the drug-resistant HER2 K753E and L755S mutations were enriched in metastatic lesions [76].

In their study of breast tumors with amplified and mutated HER2, Cocco et al. showed that coincident HER2 mutation and amplification was associated with poor response to trastuzumab and lapatinib in cultured cell lines [5]. In mice, xenografts established from a patient with a HER2+ tumor with an acquired D769Y mutation in HER2 following progression on trastuzumab-based therapy were resistant to trastuzumab and lapatinib but sensitive to neratinib, which induced durable tumor shrinkage.

Clinically, the therapeutic relevance of targeting HER family mutations is exemplified by SUMMIT (NCT01953926), an ongoing, multicenter, multi-histology, phase II precision medicine 'basket' trial investigating the efficacy and safety of neratinib in patients with HER2-mutant cancers [81]. Interestingly, neratinib efficacy depended on both the specific mutation and on tumor histology, with breast, cervical, and biliary cancers showing the greatest response [81]. Given the relative scarcity of HER2 mutations, the observational genomic-screening protocol HER-Seq (NCT03786107) was designed to identify patients potentially eligible to enroll into neratinib treatment protocols such as SUMMIT, by performing HER2-targeted next-generation sequencing on plasma collected from patients with metastatic breast or cervical cancer. 


\subsection{Downstream Signaling or Gene Expression}

Differences in the characteristics of lapatinib and neratinib, as outlined above, have been shown to affect downstream signaling pathways, resulting in differential responses to each drug. The expression levels of five genes (RB1CC1, FOXO3a, NR3C1, ERBB3 and CCND1 [cyclin D1]) were altered by lapatinib treatment, in proportion to lapatinib sensitivity [68]. A follow-up study examined the expression of these genes in response to lapatinib, neratinib, and afatinib in three HER2+ cell lines (TKI-sensitive SKBR3 and BT474, and lapatinib-insensitive MDA-MB-453) using TaqMan ${ }^{\mathrm{TM}}$ real-time polymerase chain reaction [69]. Lapatinib and neratinib were reported to have a similar impact pattern on the gene panel across all three cell lines, although the magnitude of change in four of the five genes was greater in neratinib- versus lapatinib-treated SKBR3 and BT474 cells. CCND1 levels have also been reported to be altered following neratinib treatment [48].

A quantitative, label-free, liquid chromatography-mass spectrometry proteomic approach was used to investigate cell line models of HER2+ breast cancer following short-term treatment with TKIs [82]. Twelve-hour treatment with lapatinib, neratinib, and afatinib was examined in the BT474 cell line. Twenty-one proteins were altered significantly in response to neratinib $(150 \mathrm{nM})$, whereas 16 proteins were altered significantly in response to lapatinib $(1 \mu \mathrm{M})$. Within this dataset, six proteins had altered levels in response to short-term exposure to both lapatinib and neratinib but not afatinib (lamina-associated polypeptide 2 isoform $\alpha$, DNA-dependent protein kinase catalytic subunit, drebrin, myristoylated alanine-rich C-kinase substrate, $78 \mathrm{kDa}$ glucose-regulated protein, and poly[ADP-ribose] polymerase 1). Three proteins were co-altered by afatinib and neratinib but not lapatinib (heterogeneous nuclear ribonucleoprotein $\mathrm{H}$, interleukin enhancer-binding factor 3 , and trifunctional enzyme subunit beta, mitochondrial), which are involved in mRNA splicing, apoptosis/protein metabolism, and protein acetylation, respectively. Finally, only two proteins were co-altered in response to all three inhibitors (trifunctional enzyme subunit $\alpha$ and heterogeneous nuclear riboprotein $\mathrm{R}$ ). The breadth of function of these proteins indicates the potential implications that inter-TKI differences could have in tumor cell responses to these therapies. The protein products of the genes examined as part of the five-gene panel [69] were not apparent in the proteomics study, which may be related to temporal differences between RNA and protein expression in response to drug exposure.

\subsection{HER2 Receptor Levels and Endocytosis}

Cell surface levels of RTKs are regulated by endocytosis, a process through which RTKs are internalized into endosomes, where they can be recycled back to the cell surface or progress to lysosomes for degradation; this process is accelerated by ligand binding [83]. EGFR homodimerization and EGFR/HER2 heterodimerization occur with comparable affinities, and EGFR/HER2 complexes internalize as a single entity [84]. Studies of HER2 internalization have revealed a dependency on the chaperone heat-shock protein (HSP) 90 for stability at the cell surface $[85,86]$. HSP90 inhibitors can induce HER2 degradation through proteasomal or lysosomal pathways, which are regulated by ubiquitylation [87-89]. NVP-AUY922, an HSP90 inhibitor, has been reported to inhibit growth of HER2+ and trastuzumab-resistant breast cancer cells [90]. In vitro, NVP-AUY922 enhanced response to trastuzumab but not to chemotherapy. Nuclear localization of ligand-activated HER3 in proliferating cells has been associated with a clathrin-independent endocytic mechanism [91]. The internalization and lysosome targeting of HER2, HER3, and HER4 are reported to be less efficient than those of EGFR, suggesting that EGFR regulation could be affected by overexpression of other family members [86].

Evidence has accumulated that lapatinib and neratinib have differential effects on cell surface levels of HER2, with lapatinib increasing and neratinib decreasing levels [42,92]. Zhang et al. provided a hypothesis for the underlying mechanism responsible for these effects. In three HER2+ cell lines (SKBR3, AU565, and HCC1954), neratinib augmented endocytic degradation of HER2 through increased ubiquitylation, with only moderate increases in HER2 transcription, whereas lapatinib led to strong upregulation of HER2 transcription and more limited HER2 endocytosis (Figure 4A) [59]. 
A

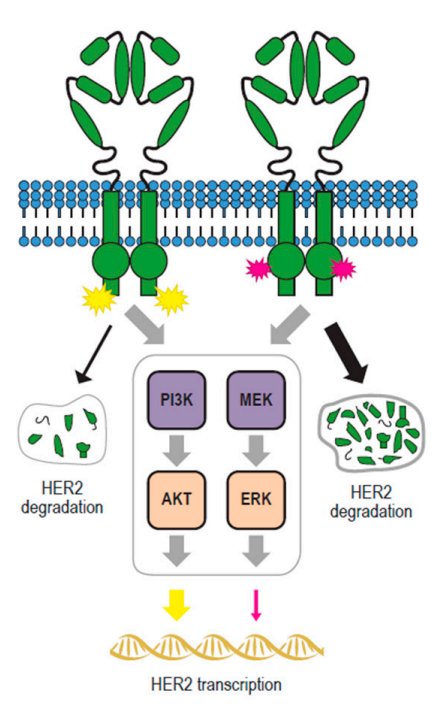

B

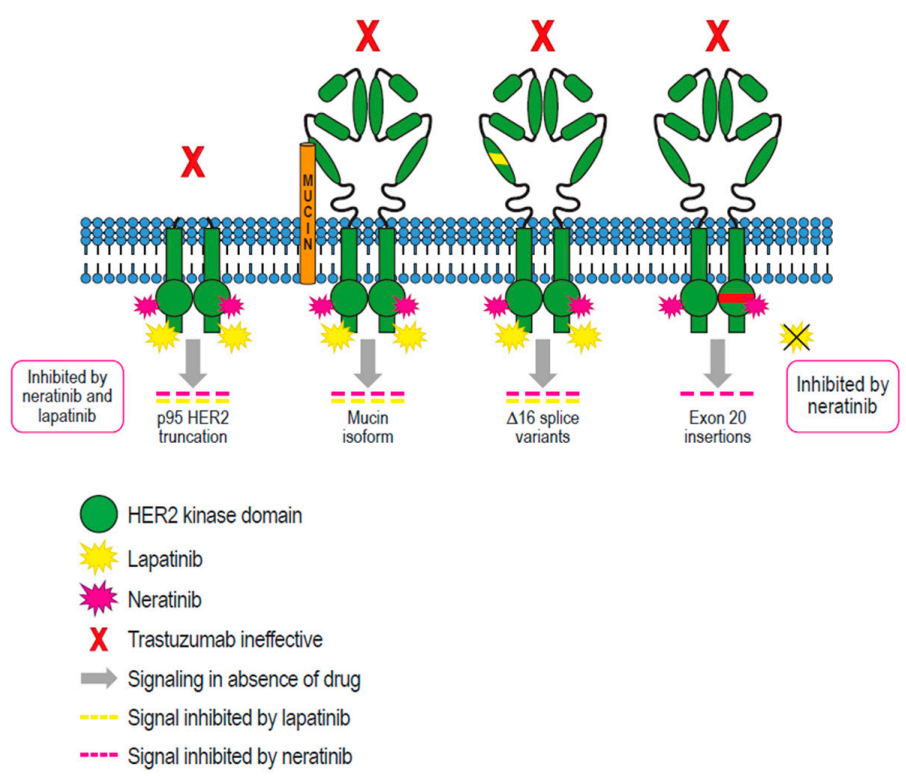

Figure 4. (A) Schematic representation of HER2 regulation by lapatinib and neratinib via elevation of HER2 transcription and endocytosis as proposed by Zhang et al. [59]. The differential effects of neratinib and lapatinib are indicated by weighted arrows, with thicker arrows corresponding to a greater effect. Both lapatinib and neratinib increase HER2 transcription through inhibition of PI3K and MAPK signaling, but lapatinib to a greater extent. Both tyrosine kinase inhibitors increase endocytosis and lysosomal degradation of HER2 but neratinib leads to greater HER2 ubiquitylation and degradation than lapatinib [59]. The net effect is an increase in cellular HER2 levels with lapatinib exposure and a decrease in cellular HER2 levels following exposure to neratinib. (B) Schematic depiction of HER2-related mechanisms implicated in resistance to trastuzumab, lapatinib, and neratinib. Adapted from Arteaga and Engelmen [79] and references cited therein. Trastuzumab (or pertuzumab/T-DM1) cannot bind truncated p95 HER2. Expression of specific mucin isoforms can abrogate trastuzumab binding. The $\triangle 16$ HER2 splice variant, which has an in-frame deletion of 16 amino acids (634-649) of exon 16 in domain IV, does not bind trastuzumab. The $\Delta 16$ HER2 splice variant co-exists with wild-type HER2 and can promote transformation through constitutively active homodimer formation and enhanced signaling activity [93]. All three mechanisms mediate resistance to trastuzumab but are susceptible to lapatinib and neratinib inhibition. The P780_Y781insGSP exon 20 insertion in the HER2 kinase domain has been shown to mediate resistance to lapatinib and trastuzumab, but not neratinib, in a breast cancer cell line model [75]. AKT, protein kinase B; ERK, extracellular signal-regulated kinase; HER, human epidermal growth factor receptor; MEK, mitogen-activated protein kinase kinase; PI3K, phosphoinositide 3-kinase; T-DM1, trastuzumab emtansine.

The impact of TKI-altered HER2 levels on ADCC response to trastuzumab has been investigated as a potential rationale for their combination. Lapatinib-induced increases in HER2 resulted in increased trastuzumab-mediated ADCC in HER2+ breast, gastric, and mesothelioma cell line models [42,92,94-96]. However, the impact of lapatinib and neratinib on ADCC may be dependent on factors other than HER2 antigen levels, as both TKIs led to increases in ADCC in vitro, dependent on the cytotoxic capacity of immune effector cells involved [92]. Profiling of lapatinib- and neratinib-resistant HER2+ breast cancer cell lines showed that a TKI resistance phenotype in vitro is associated with reduced trastuzumab-related ADCC, which can also be independent of HER2 expression levels [97,98].

The ECD of HER2 can be cleaved by matrix metalloproteinases to release a soluble form of HER2 (sHER2) into the peripheral circulation [99]. A high baseline level of circulating sHER2 is prognostic for shorter disease-free survival in early-stage, resected HER2+ breast cancer; high sHER2 levels at recurrence also predict shorter survival [100]. Trastuzumab has been shown to inhibit sHER2 shedding 
by inhibiting basal and activated proteolytic cleavage of HER2 [101]. Conversely, lapatinib increases inactive HER2 levels at the tumor cell surface and augments release of sHER2 [102]. Higher sHER2 levels predict improved progression-free survival with lapatinib treatment independent of tumor levels of HER2 in patients with advanced breast cancer [103]. Similar data are not currently available for neratinib.

\section{Resistance to Lapatinib and Neratinib}

Despite the clinical successes seen with HER2-targeted therapies, development of resistance is an ongoing problem. In vitro cell line models have been used extensively to examine possible mechanisms of resistance to lapatinib and neratinib. This involves either continuous exposure to the TKI, dose-escalation treatment, or single cell cloning. Section 4.5 details mutations associated with TKI resistance. Some possible resistance mechanisms are shown in Figure 4B.

\subsection{Lapatinib Resistance}

Many potential lapatinib resistance mechanisms have been proposed. These can be categorized broadly as: activation of alternative tensin homolog RTKs; downstream reactivation of PI3K or MAPK signaling; or phenotypic switching.

Although proliferation of HER2+ breast cancer cells is driven by HER2 signaling, redundant survival mechanisms can be activated when HER2 signaling is suppressed. These include upregulation of other RTKs, such as alternative HER family members, MET, fibroblast growth factor receptor-2, and insulin-like growth factor-1 receptor [104-106]. In one study using four cell lines with acquired lapatinib resistance, lapatinib inhibited HER2 activity but downstream PI3K signaling persisted, despite an absence of PIK3CA mutation or phosphatase and tensin homolog (PTEN) loss [107]. Resistance was mediated by EGFR-HER3 dimerization, which was regulated by increased levels of membrane-bound heregulin. Interestingly, neratinib overcame this lapatinib resistance. HER4 signaling may also be a mechanism of resistance: Canfield et al. showed that HER2+ breast cancer cell line models of lapatinib and trastuzumab resistance (BT474-LR, SKBR3-TR, SKBR3-LR, and SKBR3-LTR) were dependent on HER4 expression for survival, unlike their parent cell lines [108]. The authors suggested that the efficacy of several pan-HER family inhibitors (afatinib, canertinib, dacomitinib, varlitinib, and neratinib) in lapatinib-resistant HER2+ breast cancer models was potentially dependent on their ability to inhibit HER4 activity. The authors also reported the findings of an in vivo study, which showed membranous tumor HER4 expression in all lapatinib-treated HER2+ tumors [108].

Alternatively, lapatinib resistance may occur through downstream reactivation of PI3K, which may be due to activation by Src family kinases, through insulin receptor substrate 4 , an indirect cytoplasmic activator of PIK3CA, or by the acquisition of PIK3CA or HER2 mutations [109-111].

ER pathway activation may also cause HER2-targeted therapy resistance. Li et al. showed that, despite continued inhibition of HER2 and PIK3CA, BT474 cells with acquired lapatinib resistance proliferated in the presence of $5 \mu \mathrm{M}$ lapatinib as a result of increased ER and MAPK signaling, which could be overcome by addition of fulvestrant [112]. Protein phosphatase 2A (PP2A) may also confer lapatinib resistance in vitro: increased PP2A activity was demonstrated in two cell lines with acquired lapatinib resistance, with PP2A inhibition leading to lapatinib resensitization [113].

Epithelial-mesenchymal transition (EMT) results in a stem-like phenotype associated with resistance to anti-cancer therapy $[114,115]$. Preclinical studies have implicated EMT in the emergence of HER2-targeted therapy resistance [116]. Lapatinib-resistant SKBR3 cells displayed EMT markers as well as reduced HER2 expression, and an epithelial-like phenotype could be re-established using the anti-integrin inhibitory antibody AIIB2 [117].

\subsection{Neratinib Resistance}

Despite its relatively recent approval for treatment of HER2+ breast cancer, several mechanisms of resistance to neratinib have been proposed, including decreased pro-apoptotic BCL2 family member 
expression, and increased cytochrome P450 (CYP) 3A4 activity [71,118]. Using neratinib-resistant HER2+ cell lines derived from SKBR3, ZR75-30, and BT474, Karakas et al. reported increased levels of anti-apoptotic MCL-1 and decreased levels of pro-apoptotic BCL2 family members BIM and p53 upregulated modulator of apoptosis (PUMA) in neratinib-resistant SKBR3 and ZR75-30 cells [118]. Neratinib-resistant BT474 cells also exhibited downregulated BIM and PUMA and increased BCL2 and BCL-XL levels in order to overcome neratinib-induced apoptosis [118]. Furthermore, these cell lines showed continued downstream activation of ERK-1/2, despite neratinib treatment. These neratinib-resistant cell lines were examined for sensitivity to ERK inhibition using the specific ERK1/2 inhibitor SCH772984, and sensitivity to BCL2/BCL-XL inhibition using the pan-BCL2 inhibitor ABT-737. Although the combination of neratinib and SCH772984 induced apoptosis in SKBR3-NR and ZR75-30-NR, the triple combination of neratinib, SCH772984, and ABT-737 was required to overcome neratinib resistance in BT474-NR cells [118].

Neratinib is also a substrate for CYP3A4, and increased CYP3A4 activity has been shown to cause neratinib resistance in cell line models. Breslin et al. developed HCC1954-NR and EFM192A-NR cell lines through continuous exposure to neratinib in vitro. These cell lines were not only neratinib resistant, but also cross-resistant to lapatinib and afatinib, more migratory and invasive than their parent cells, and displayed decreased HER2 expression [71].

The significance of PI3K pathway activation as a mechanism of resistance to neratinib has been inconsistent, appearing to depend on tumor type and disease setting. Preclinically, neratinib inhibited proliferation in HER2-amplified, PIK3CA-mutant tumor cell lines [73], and inhibited tumor growth in a HER2-positive, PIK3CA-mutant patient-derived xenograft model [119]. In the positive phase III ExteNET study, which compared 1 year of neratinib versus placebo given in the adjuvant setting after standard trastuzumab-based therapy, absolute risk reduction was associated with neratinib treatment of patients with PIK3CA-mutated or -amplified cancers, although this reduction was not statistically significant [120]. In the first 125 patients from the SUMMIT basket trial for HER2-mutant, metastatic solid tumors who were treated with neratinib monotherapy, PIK3CA mutations were more prevalent in patients who were on treatment for $<24$ weeks than those who were on for $\geq 24$ weeks, although this difference was not statistically significant [81]. Larger clinical trials in specific tumor types may be required to determine the effect of PIK3CA mutation on response to neratinib in HER2-driven cancer.

In a recent study, Sudhan et al. demonstrated that the neratinib-resistant 5637 and OVCAR8 cell lines with activating HER2 mutations, which had increased S6 kinase activity and S6 phosphorylation compared with neratinib-sensitive parental cells, were cross-resistant to lapatinib and afatinib [121]. S6 activation was primarily mediated by mammalian target of rapamycin (mTOR) complex 1 (mTORC1) pathway activation, which was attributed at least in part to RAS pathway upregulation; the combination of neratinib and everolimus overcame neratinib resistance in vitro and in vivo. Furthermore, patients with mTOR-activating alterations co-occurring with HER2 mutations responded poorly to neratinib in the SUMMIT study [81]. The authors concluded that mTOR pathway alterations leading to reactivation of the HER2 signaling axis are important drivers of neratinib resistance in histologically distinct types of HER2-mutant cancers and that the combination of neratinib and mTORC1 inhibitors may be of clinical interest in patients with HER2-mutant cancers with mTOR pathway co-mutations [121]. Somatic HER2 mutations may also have a role to play in neratinib resistance, with acquisition of a T798I gatekeeper mutation recently being reported in a neratinib-treated patient with ER+/HER2-mutant (L869R) breast cancer [78].

Other second-site ("on-target") HER2 mutations and amplifications have been detected in a subset of patients with HER2 mutation-positive cancers progressing on treatment with neratinib in the SUMMIT trial. This suggests that hyperactivation of HER kinase signaling beyond a threshold of effective neratinib inhibition may be conferring both de novo and acquired resistance to therapy [122]. 


\section{Novel Targeted Therapy Combinations}

As suggested in Section 4.2, differences in the properties of lapatinib and neratinib are likely to impact efficacy when combined with other targeted agents. Histone deacetylases (HDACs) and histone acetyltransferases (HATs) play key roles in the epigenetic regulation of gene expression. HDAC inhibitors have multiple effects on cancer cells: cell cycle arrest, differentiation, and cell death; reduction of angiogenesis; and impact on the immune response [123]. The combination of lapatinib and entinostat has exhibited synergy in two in vivo models of HER2+ breast cancer (BT474 and SUM190), and entinostat-resensitized trastuzumab/lapatinib-resistant cell lines to lapatinib through induction of BIM1 [124]. The cytotoxicity of neratinib can be enhanced by HDAC inhibitors, with the added benefit that this combination has been shown to improve the anti-tumor immune response in preclinical models of afatinib-resistant non-small cell lung and breast cancers [125]. Addition of the cyclin-dependent kinase (CDK)4/6 inhibitor palbociclib to neratinib plus the HDAC inhibitor valproate suppressed growth of a patient-derived platinum/taxane-resistant ovarian xenograft model [126]. Neratinib plus valproate also enhanced the efficacy of a programmed cell death-1 (PD-1) antibody in a mouse syngeneic breast cancer model [125].

P-glycoprotein (P-gp; multidrug resistance protein 1 [MDR1]/ATP-binding cassette sub-family B member 1 [ABCB1]) is a drug efflux pump with a physiological role in the pharmacokinetics and pharmacodynamics of drugs, and it is a major mediator of tumor multidrug resistance [127]. Lapatinib and neratinib have been shown to function as P-gp inhibitors capable of reversing multidrug resistance in vitro $[10,11,128]$. Lapatinib has been shown to increase P-gp in cancer cell line models, while neratinib has been shown to do the opposite [71,129]. Further work is required to determine if these effects are dependent on the cell line lineage. The inhibition of P-gp by both TKIs could be considered a secondary anti-tumor function and combining lapatinib and neratinib with P-gp substrate chemotherapeutics may have value in P-gp overexpressing tumors.

The ER is known to play a role in resistance to HER2-targeted therapies as a compensatory signaling pathway $[130,131]$. Addition of anti-estrogens to lapatinib and neratinib has been shown to be of value in preclinical models [132,133]. The more complete inhibition of HER family signaling by neratinib versus lapatinib (Table 1) may further eliminate the HER family as a bypass pathway in the presence of ER inhibition, increasing the efficacy of anti-estrogens. The combination of neratinib and anti-estrogens is also synergistic in HER2-mutant models [134].

In addition, following ligand-induced proteolytic cleavage, the intracellular domain of HER4 (4ICD) has been shown to act as a co-activator of ER in the nucleus of ER+/HER2-low cells $[135,136]$. Unlike lapatinib, the ability of neratinib to potently inhibit HER4 may negatively impact the transcriptional co-factor activity of 4ICD. Neratinib plus fulvestrant is being examined in the ER+/HER2-mutant setting in the SUMMIT trial. Investigating 4ICD levels and localization in translational material from such trials may elucidate any mechanistic role for 4ICD in response to neratinib and anti-estrogens.

Other combinations have also shown synergy in preclinical models. The multi-kinase inhibitor regorafenib has displayed synergy with lapatinib in preclinical models of colorectal cancer [137]. In addition, lapatinib enhanced the mammary HER2+ tumor growth-suppression effects of regorafenib and the phosphodiesterase- 5 inhibitor sildenafil in vivo [138]. Neratinib has exhibited the same ability to enhance the anti-tumor effects of the regorafenib/sildenafil combination in colon cancer cells in vivo [139].

\section{Conclusions}

Three key properties differentiate the preclinical activities of neratinib and lapatinib: the breadth of targets for neratinib in the HER family of receptors; the greater potency of neratinib versus lapatinib; and the ability of neratinib to irreversibly inhibit EGFR and HER2/4. These properties outline a clear advantage for neratinib in vitro when assessing the cytotoxicity of these TKIs in treatment-naive, treatment-resistant, and HER-mutated breast cancer models. The impact of more 
complete HER-family inhibition extends to the potential impact of neratinib on trastuzumab-mediated ADCC and combination with novel targeted therapies.

The extent to which neratinib's irreversible, potent, and pan-HER binding in preclinical models influences the clinical profile of this TKI, in particular in relation to that of lapatinib, remains to be determined. To date, the only randomized study comparing neratinib and lapatinib is the phase III NALA trial investigating neratinib plus capecitabine versus lapatinib plus capecitabine in patients with third-line HER2-positive metastatic breast cancer (NCT01808573). Top-line results indicate that treatment with neratinib plus capecitabine resulted in a statistically significant improvement in centrally confirmed progression-free survival and trended positively for overall survival versus lapatinib plus capecitabine [140]. The results of the trial also showed that treatment with neratinib plus capecitabine statistically significantly improved time to intervention for symptomatic brain metastases, a secondary endpoint of the study, versus lapatinib plus capecitabine. Prophylactic treatment for diarrhea has improved the major clinical side effect of neratinib [141], allowing further investigation of neratinib in additional clinical settings for patients with HER2-positive or HER2-mutated tumors. Given its unique potent, irreversible, pan-HER kinase inhibitor properties, neratinib has potential to synergize with a variety of molecular targeted therapies, such as trastuzumab, T-DM1, anti-estrogens, Src inhibitors, CDK4/6 inhibitors, HSP90 inhibitors, and HDAC inhibitors, in the treatment-naive or treatment-refractory settings. Indeed, several combination strategies have demonstrated proof of concept in preclinical models and encouraging activity in early clinical trials and further findings from ongoing research with neratinib are awaited with interest.

Author Contributions: All authors have contributed to writing, revision, and approval of the final form of the manuscript.

Funding: This review article and associated page charges were funded by Puma Biotechnology, Inc.

Acknowledgments: Denis M. Collins is supported by the Cancer Clinical Research Trust (CHY12210) and The Caroline Foundation. Puma Biotechnology supported the provision of medical writing support provided by Lee Miller and Deirdre Carman of Miller Medical Communications (UK).

Conflicts of Interest: C.S.V. and S.K. are the founders of Sinopsee Therapeutics, a biotechnology company developing molecules for therapeutic purposes; the current work has no conflict with the company. D.M.C., N.T.C. and J.C. have received research funding from Puma Biotechnology, Inc. D.M.C. has received consultancy fees from Puma Biotechnology, Inc. J.C. has participated in advisory boards for Puma Biotechnology, Inc. and Novartis Oncology. A.S.L. and L.D.E. are employees and shareholders of Puma Biotechnology, Inc.

\section{References}

1. Escriva-de-Romani, S.; Arumi, M.; Bellet, M.; Saura, C. HER2-positive breast cancer: Current and new therapeutic strategies. Breast 2018, 39, 80-88. [CrossRef] [PubMed]

2. Moulder, S.L.; Borges, V.F.; Baetz, T.; McSpadden, T.; Fernetich, G.; Murthy, R.K.; Chavira, R.; Guthrie, K.; Barrett, E.; Chia, S.K. Phase I study of ONT-380, a HER2 inhibitor, in patients with HER2(+)-advanced solid tumors, with an expansion cohort in HER2(+) metastatic breast cancer (MBC). Clin. Cancer Res. 2017, 23, 3529-3536. [CrossRef] [PubMed]

3. Kim, T.M.; Lee, K.W.; Oh, D.Y.; Lee, J.S.; Im, S.A.; Kim, D.W.; Han, S.W.; Kim, Y.J.; Kim, T.Y.; Kim, J.H.; et al. Phase 1 studies of poziotinib, an irreversible pan-HER tyrosine kinase inhibitor in patients with advanced solid tumors. Cancer Res. Treat. 2018, 50, 835-842. [CrossRef] [PubMed]

4. Li, X.; Yang, C.; Wan, H.; Zhang, G.; Feng, J.; Zhang, L.; Chen, X.; Zhong, D.; Lou, L.; Tao, W.; et al. Discovery and development of pyrotinib: A novel irreversible EGFR/HER2 dual tyrosine kinase inhibitor with favorable safety profiles for the treatment of breast cancer. Eur. J. Pharm. Sci. 2017, 110, 51-61. [CrossRef] [PubMed]

5. Cocco, E.; Javier Carmona, F.; Razavi, P.; Won, H.H.; Cai, Y.; Rossi, V.; Chan, C.; Cownie, J.; Soong, J.; Toska, E.; et al. Neratinib is effective in breast tumors bearing both amplification and mutation of ERBB2 (HER2). Sci. Signal. 2018, 11. [CrossRef] [PubMed]

6. Connell, C.M.; Doherty, G.J. Activating HER2 mutations as emerging targets in multiple solid cancers. ESMO Open 2017, 2, e000279. [CrossRef] [PubMed] 
7. Davis, M.I.; Hunt, J.P.; Herrgard, S.; Ciceri, P.; Wodicka, L.M.; Pallares, G.; Hocker, M.; Treiber, D.K.; Zarrinkar, P.P. Comprehensive analysis of kinase inhibitor selectivity. Nat. Biotechnol. 2011, 29, 1046-1051. [CrossRef] [PubMed]

8. Novartis Pharmaceuticals Corporation. Lapatinib Prescribing Information. Available online: https: //www.accessdata.fda.gov/drugsatfda_docs/label/2010/022059s007lbl.pdf (accessed on 1 March 2019).

9. Puma Biotechnology. Neratinib Prescribing Information. Available online: https://nerlynx.com/pdf/fullprescribing-information.pdf (accessed on 1 March 2019).

10. Collins, D.M.; Crown, J.; O’Donovan, N.; Devery, A.; O'Sullivan, F.; O’Driscoll, L.; Clynes, M.; O'Connor, R. Tyrosine kinase inhibitors potentiate the cytotoxicity of MDR-substrate anticancer agents independent of growth factor receptor status in lung cancer cell lines. Investig. New Drugs 2010, 28, 433-444. [CrossRef]

11. Zhao, X.Q.; Xie, J.D.; Chen, X.G.; Sim,H.M.; Zhang, X.; Liang, Y.J.; Singh, S.; Talele, T.T.; Sun, Y.; Ambudkar, S.V.; et al. Neratinib reverses ATP-binding cassette B1-mediated chemotherapeutic drug resistance in vitro, in vivo, and ex vivo. Mol. Pharmacol. 2012, 82, 47-58. [CrossRef]

12. Frankel, C.; Palmieri, F.M. Lapatinib side-effect management. Clin. J. Oncol. Nurs. 2010, 14, $223-233$. [CrossRef]

13. Friedman, M.D.; Lacouture, M.; Dang, C. Dermatologic adverse events associated with use of adjuvant lapatinib in combination with paclitaxel and trastuzumab for HER2-positive breast cancer: A case series analysis. Clin. Breast Cancer 2016, 16, e69-e74. [CrossRef] [PubMed]

14. Singh,H.; Walker, A.J.; Amiri-Kordestani, L.; Cheng, J.; Tang, S.; Balcazar, P.; Barnett-Ringgold, K.; Palmby, T.R.; Cao, X.; Zheng, N.; et al. U.S. Food and drug administration approval: Neratinib for the extended adjuvant treatment of early-stage HER2-positive breast cancer. Clin. Cancer Res. 2018, 24, 3486-3491. [CrossRef] [PubMed]

15. Roskoski, R., Jr. The ErbB/HER family of protein-tyrosine kinases and cancer. Pharmacol. Res. 2014, 79, 34-74. [CrossRef] [PubMed]

16. Yarden, Y.; Sliwkowski, M.X. Untangling the ErbB signalling network. Nat. Rev. Mol. Cell Biol. 2001, 2, 127-137. [CrossRef] [PubMed]

17. Roskoski, R., Jr. ErbB/HER protein-tyrosine kinases: Structures and small molecule inhibitors. Pharmacol. Res. 2014, 87, 42-59. [CrossRef] [PubMed]

18. Cho, H.S.; Mason, K.; Ramyar, K.X.; Stanley, A.M.; Gabelli, S.B.; Denney, D.W., Jr.; Leahy, D.J. Structure of the extracellular region of HER2 alone and in complex with the Herceptin Fab. Nature 2003, 421, 756-760. [CrossRef] [PubMed]

19. Falls, D.L. Neuregulins: Functions, forms, and signaling strategies. Exp. Cell Res. 2003, 284, 14-30. [CrossRef]

20. Peles, E.; Lamprecht, R.; Ben-Levy, R.; Tzahar, E.; Yarden, Y. Regulated coupling of the Neu receptor to phosphatidylinositol 3'-kinase and its release by oncogenic activation. J. Biol. Chem. 1992, 267, 12266-12274.

21. Stein, R.A.; Staros, J.V. Evolutionary analysis of the ErbB receptor and ligand families. J. Mol. Evol. 2000, 50, 397-412. [CrossRef]

22. Shankaran, H.; Zhang, Y.; Tan, Y.; Resat, H. Model-based analysis of HER activation in cells co-expressing EGFR, HER2 and HER3. PLoS Comput. Biol. 2013, 9, e1003201. [CrossRef]

23. Brennan, P.J.; Kumagai, T.; Berezov, A.; Murali, R.; Greene, M.I. HER2/neu: Mechanisms of dimerization/oligomerization. Oncogene 2000, 19, 6093-6101. [CrossRef] [PubMed]

24. Segovia-Mendoza, M.; Diaz, L.; Prado-Garcia, H.; Reginato, M.J.; Larrea, F.; Garcia-Becerra, R. The addition of calcitriol or its synthetic analog EB1089 to lapatinib and neratinib treatment inhibits cell growth and promotes apoptosis in breast cancer cells. Am. J. Cancer Res. 2017, 7, 1486-1500. [PubMed]

25. Kourie, H.R.; Chaix, M.; Gombos, A.; Aftimos, P.; Awada, A. Pharmacodynamics, pharmacokinetics and clinical efficacy of neratinib in HER2-positive breast cancer and breast cancer with HER2 mutations. Expert Opin. Drug Metab. Toxicol. 2016, 12, 947-957. [CrossRef] [PubMed]

26. Appert-Collin, A.; Hubert, P.; Cremel, G.; Bennasroune, A. Role of ErbB receptors in cancer cell migration and invasion. Front. Pharmacol. 2015, 6, 283. [CrossRef] [PubMed]

27. Ross, J.S.; Slodkowska, E.A.; Symmans, W.F.; Pusztai, L.; Ravdin, P.M.; Hortobagyi, G.N. The HER-2 receptor and breast cancer: Ten years of targeted anti-HER-2 therapy and personalized medicine. Oncologist 2009, 14, 320-368. [CrossRef]

28. Yan, M.; Schwaederle, M.; Arguello, D.; Millis, S.Z.; Gatalica, Z.; Kurzrock, R. HER2 expression status in diverse cancers: Review of results from 37,992 patients. Cancer Metastasis Rev. 2015, 34, 157-164. [CrossRef] 
29. Moja, L.; Tagliabue, L.; Balduzzi, S.; Parmelli, E.; Pistotti, V.; Guarneri, V.; D'Amico, R. Trastuzumab containing regimens for early breast cancer. Cochrane Database Syst. Rev. 2012, CD006243. [CrossRef]

30. Slamon, D.J.; Leyland-Jones, B.; Shak, S.; Fuchs, H.; Paton, V.; Bajamonde, A.; Fleming, T.; Eiermann, W.; Wolter, J.; Pegram, M.; et al. Use of chemotherapy plus a monoclonal antibody against HER2 for metastatic breast cancer that overexpresses HER2. N. Engl. J. Med. 2001, 344, 783-792. [CrossRef]

31. Sierra, J.R.; Cepero, V.; Giordano, S. Molecular mechanisms of acquired resistance to tyrosine kinase targeted therapy. Mol. Cancer 2010, 9, 75. [CrossRef]

32. Arribas, J.; Baselga, J.; Pedersen, K.; Parra-Palau, J.L. p95HER2 and breast cancer. Cancer Res. 2011, 71, 1515-1519. [CrossRef]

33. Ryan, Q.; Ibrahim, A.; Cohen, M.H.; Johnson, J.; Ko, C.W.; Sridhara, R.; Justice, R.; Pazdur, R. FDA drug approval summary: Lapatinib in combination with capecitabine for previously treated metastatic breast cancer that overexpresses HER-2. Oncologist 2008, 13, 1114-1119. [CrossRef] [PubMed]

34. Schwartzberg, L.S.; Franco, S.X.; Florance, A.; O’Rourke, L.; Maltzman, J.; Johnston, S. Lapatinib plus letrozole as first-line therapy for HER-2+ hormone receptor-positive metastatic breast cancer. Oncologist 2010, 15, 122-129. [CrossRef] [PubMed]

35. European Medicines Agency. Tyverb Summary of Product Characteristics. Available online: https: //www.ema.europa.eu/documents/product-information/tyverb-epar-product-information_en.pdf (accessed on 1 March 2019).

36. Rusnak, D.W.; Lackey, K.; Affleck, K.; Wood, E.R.; Alligood, K.J.; Rhodes, N.; Keith, B.R.; Murray, D.M.; Knight, W.B.; Mullin, R.J.; et al. The effects of the novel, reversible epidermal growth factor receptor/ErbB-2 tyrosine kinase inhibitor, GW2016, on the growth of human normal and tumor-derived cell lines in vitro and in vivo. Mol. Cancer Ther. 2001, 1, 85-94. [PubMed]

37. Konecny, G.E.; Pegram, M.D.; Venkatesan, N.; Finn, R.; Yang, G.; Rahmeh, M.; Untch, M.; Rusnak, D.W.; Spehar, G.; Mullin, R.J.; et al. Activity of the dual kinase inhibitor lapatinib (GW572016) against HER-2-overexpressing and trastuzumab-treated breast cancer cells. Cancer Res. 2006, 66, 1630-1639. [CrossRef] [PubMed]

38. Martin, A.P.; Mitchell, C.; Rahmani, M.; Nephew, K.P.; Grant, S.; Dent, P. Inhibition of MCL-1 enhances lapatinib toxicity and overcomes lapatinib resistance via BAK-dependent autophagy. Cancer Biol. Ther. 2009, 8, 2084-2096. [CrossRef] [PubMed]

39. Mitchell, C.; Yacoub, A.; Hossein, H.; Martin, A.P.; Bareford, M.D.; Eulitt, P.; Yang, C.; Nephew, K.P.; Dent, P. Inhibition of MCL-1 in breast cancer cells promotes cell death in vitro and in vivo. Cancer Biol. Ther. 2010, 10, 903-917. [CrossRef] [PubMed]

40. Tanizaki, J.; Okamoto, I.; Fumita, S.; Okamoto, W.; Nishio, K.; Nakagawa, K. Roles of BIM induction and survivin downregulation in lapatinib-induced apoptosis in breast cancer cells with HER2 amplification. Oncogene 2011, 30, 4097-4106. [CrossRef]

41. Xia, W.; Bisi, J.; Strum, J.; Liu, L.; Carrick, K.; Graham, K.M.; Treece, A.L.; Hardwicke, M.A.; Dush, M.; Liao, Q.; et al. Regulation of survivin by ErbB2 signaling: Therapeutic implications for ErbB2-overexpressing breast cancers. Cancer Res. 2006, 66, 1640-1647. [CrossRef]

42. Scaltriti, M.; Verma, C.; Guzman, M.; Jimenez, J.; Parra, J.L.; Pedersen, K.; Smith, D.J.; Landolfi, S.; Ramon y Cajal, S.; Arribas, J.; et al. Lapatinib, a HER2 tyrosine kinase inhibitor, induces stabilization and accumulation of HER2 and potentiates trastuzumab-dependent cell cytotoxicity. Oncogene 2009, 28, 803-814. [CrossRef]

43. Kannan, S.; Pradhan, M.R.; Tiwari, G.; Tan, W.C.; Chowbay, B.; Tan, E.H.; Tan, D.S.; Verma, C. Hydration effects on the efficacy of the epidermal growth factor receptor kinase inhibitor afatinib. Sci. Rep. 2017, 7, 1540. [CrossRef]

44. Case, D.A.; Berryman, J.T.; Betz, R.M.; Cerutti, D.S.; Cheatham, T.E., III; Darden, T.A.; Duke, R.E.; Giese, T.J.; Gohlke, H.; Goetz, A.W.; et al. AMBER 6; University of California: San Francisco, CA, USA, 2016.

45. Maier, J.A.; Martinez, C.; Kasavajhala, K.; Wickstrom, L.; Hauser, K.E.; Simmerling, C. ff14SB: Improving the accuracy of protein side chain and backbone parameters from ff99SB. J. Chem. Theory Comput. 2015, 11, 3696-3713. [CrossRef] [PubMed]

46. European Medicines Agency. Positive Opinion on the Marketing Authorisation for Nerlynx (Neratinib). Outcome of Re-Examination. Available online: https://www.ema.europa.eu/documents/smop-initial/ questions-answers-positive-opinion-marketing-authorisation-nerlynx-neratinib_en.pdf (accessed on 1 March 2019). 
47. Tsou, H.R.; Overbeek-Klumpers, E.G.; Hallett, W.A.; Reich, M.F.; Floyd, M.B.; Johnson, B.D.; Michalak, R.S.; Nilakantan, R.; Discafani, C.; Golas, J.; et al. Optimization of 6,7-disubstituted-4-(arylamino)quinoline-3-carbonitriles as orally active, irreversible inhibitors of human epidermal growth factor receptor-2 kinase activity. J. Med. Chem. 2005, 48, 1107-1131. [CrossRef]

48. Rabindran, S.K.; Discafani, C.M.; Rosfjord, E.C.; Baxter, M.; Floyd, M.B.; Golas, J.; Hallett, W.A.; Johnson, B.D.; Nilakantan, R.; Overbeek, E.; et al. Antitumor activity of HKI-272, an orally active, irreversible inhibitor of the HER-2 tyrosine kinase. Cancer Res. 2004, 64, 3958-3965. [CrossRef]

49. Deeks, E.D. Neratinib: First Global Approval. Drugs 2017, 77, 1695-1704. [CrossRef] [PubMed]

50. Feldinger, K.; Kong, A. Profile of neratinib and its potential in the treatment of breast cancer. Breast Cancer 2015, 7, 147-162. [CrossRef] [PubMed]

51. Sanchez-Martin, M.; Pandiella, A. Differential action of small molecule HER kinase inhibitors on receptor heterodimerization: Therapeutic implications. Int. J. Cancer 2012, 131, 244-252. [CrossRef]

52. Claus, J.; Patel, G.; Autore, F.; Colomba, A.; Weitsman, G.; Soliman, T.N.; Roberts, S.; Zanetti-Domingues, L.C.; Hirsch, M.; Collu, F.; et al. Inhibitor-induced HER2-HER3 heterodimerisation promotes proliferation through a novel dimer interface. eLife 2018, 7. [CrossRef] [PubMed]

53. Canonici, A.; Ivers, L.; Conlon, N.T.; Pedersen, K.; Gaynor, N.; Browne, B.C.; O’Brien, N.A.; Gullo, G.; Collins, D.M.; O'Donovan, N.; et al. HER-targeted tyrosine kinase inhibitors enhance response to trastuzumab and pertuzumab in HER2-positive breast cancer. Investig. New Drugs 2018. [CrossRef]

54. Liu, Y.; Gray, N.S. Rational design of inhibitors that bind to inactive kinase conformations. Nat. Chem. Biol. 2006, 2, 358-364. [CrossRef]

55. Wood, E.R.; Truesdale, A.T.; McDonald, O.B.; Yuan, D.; Hassell, A.; Dickerson, S.H.; Ellis, B.; Pennisi, C.; Horne, E.; Lackey, K.; et al. A unique structure for epidermal growth factor receptor bound to GW572016 (Lapatinib): Relationships among protein conformation, inhibitor off-rate, and receptor activity in tumor cells. Cancer Res. 2004, 64, 6652-6659. [CrossRef]

56. Klaeger, S.; Heinzlmeir, S.; Wilhelm, M.; Polzer, H.; Vick, B.; Koenig, P.A.; Reinecke, M.; Ruprecht, B.; Petzoldt, S.; Meng, C.; et al. The target landscape of clinical kinase drugs. Science 2017, 358. [CrossRef] [PubMed]

57. Stanley, A.; Ashrafi, G.H.; Seddon, A.M.; Modjtahedi, H. Synergistic effects of various Her inhibitors in combination with IGF-1R, C-MET and Src targeting agents in breast cancer cell lines. Sci. Rep. 2017, 7, 3964. [CrossRef]

58. Leto, S.M.; Sassi, F.; Catalano, I.; Torri, V.; Migliardi, G.; Zanella, E.R.; Throsby, M.; Bertotti, A.; Trusolino, L. Sustained inhibition of HER3 and EGFR is necessary to induce regression of HER2-amplified gastrointestinal carcinomas. Clin. Cancer Res. 2015, 21, 5519-5531. [CrossRef] [PubMed]

59. Zhang, Y.; Zhang, J.; Liu, C.; Du, S.; Feng, L.; Luan, X.; Zhang, Y.; Shi, Y.; Wang, T.; Wu, Y.; et al. Neratinib induces ErbB2 ubiquitylation and endocytic degradation via HSP90 dissociation in breast cancer cells. Cancer Lett. 2016, 382, 176-185. [CrossRef] [PubMed]

60. Conlon, N.; Lowry, M.; Breslin, S.; O’Driscoll, L.; Eustace, A.J.; Crown, J.; O’Donovan, N.; Collins, D.M. Src inhibition overcomes neratinib resistance in HER2-positive breast cancer. In Proceedings of the American Association for Cancer Research Annual Meeting 2018, Chicago, IL, USA, 14-18 April 2018. Abstract 1834.

61. Wong, K.K.; Fracasso, P.M.; Bukowski, R.M.; Lynch, T.J.; Munster, P.N.; Shapiro, G.I.; Janne, P.A.; Eder, J.P.; Naughton, M.J.; Ellis, M.J.; et al. A phase I study with neratinib (HKI-272), an irreversible pan ErbB receptor tyrosine kinase inhibitor, in patients with solid tumors. Clin. Cancer Res. 2009, 15, 2552-2558. [CrossRef] [PubMed]

62. Yun, C.H.; Mengwasser, K.E.; Toms, A.V.; Woo, M.S.; Greulich, H.; Wong, K.K.; Meyerson, M.; Eck, M.J. The T790M mutation in EGFR kinase causes drug resistance by increasing the affinity for ATP. Proc. Natl. Acad. Sci. USA 2008, 105, 2070-2075. [CrossRef]

63. Sogabe, S.; Kawakita, Y.; Igaki, S.; Iwata, H.; Miki, H.; Cary, D.R.; Takagi, T.; Takagi, S.; Ohta, Y.; Ishikawa, T. Structure-based approach for the discovery of pyrrolo [3,2-d]pyrimidine-based EGFR T790M/L858R mutant inhibitors. ACS Med. Chem. Lett. 2013, 4, 201-205. [CrossRef] [PubMed]

64. Kao, J.; Salari, K.; Bocanegra, M.; Choi, Y.L.; Girard, L.; Gandhi, J.; Kwei, K.A.; Hernandez-Boussard, T.; Wang, P.; Gazdar, A.F.; et al. Molecular profiling of breast cancer cell lines defines relevant tumor models and provides a resource for cancer gene discovery. PLoS ONE 2009, 4, e6146. [CrossRef] 
65. Neve, R.M.; Chin, K.; Fridlyand, J.; Yeh, J.; Baehner, F.L.; Fevr, T.; Clark, L.; Bayani, N.; Coppe, J.P.; Tong, F.; et al. A collection of breast cancer cell lines for the study of functionally distinct cancer subtypes. Cancer Cell 2006, 10, 515-527. [CrossRef]

66. Chavez, K.J.; Garimella, S.V.; Lipkowitz, S. Triple negative breast cancer cell lines: One tool in the search for better treatment of triple negative breast cancer. Breast Dis. 2010, 32, 35-48. [CrossRef]

67. O’Brien, N.A.; Browne, B.C.; Chow, L.; Wang, Y.; Ginther, C.; Arboleda, J.; Duffy, M.J.; Crown, J.; O'Donovan, N.; Slamon, D.J. Activated phosphoinositide 3-kinase/AKT signaling confers resistance to trastuzumab but not lapatinib. Mol. Cancer Ther. 2010, 9, 1489-1502. [CrossRef] [PubMed]

68. O'Neill, F.; Madden, S.F.; Aherne, S.T.; Clynes, M.; Crown, J.; Doolan, P.; O'Connor, R. Gene expression changes as markers of early lapatinib response in a panel of breast cancer cell lines. Mol. Cancer 2012, 11, 41. [CrossRef] [PubMed]

69. O’Neill, F.; Madden, S.F.; Clynes, M.; Crown, J.; Doolan, P.; Aherne, S.T.; O'Connor, R. A gene expression profile indicative of early stage HER2 targeted therapy response. Mol. Cancer 2013, 12, 69. [CrossRef] [PubMed]

70. Segovia-Mendoza, M.; Gonzalez-Gonzalez, M.E.; Barrera, D.; Diaz, L.; Garcia-Becerra, R. Efficacy and mechanism of action of the tyrosine kinase inhibitors gefitinib, lapatinib and neratinib in the treatment of HER2-positive breast cancer: Preclinical and clinical evidence. Am. J. Cancer Res. 2015, 5, 2531-2561. [PubMed]

71. Breslin, S.; Lowry, M.C.; O'Driscoll, L. Neratinib resistance and cross-resistance to other HER2-targeted drugs due to increased activity of metabolism enzyme cytochrome P4503A4. Br. J. Cancer 2017, 116, 620-625. [CrossRef] [PubMed]

72. Xu, X.; De Angelis, C.; Burke, K.A.; Nardone, A.; Hu, H.; Qin, L.; Veeraraghavan, J.; Sethunath, V.; Heiser, L.M.; Wang, N.; et al. HER2 reactivation through acquisition of the HER2 L755S mutation as a mechanism of acquired resistance to HER2-targeted therapy in HER2(+) breast cancer. Clin. Cancer Res. 2017, 23, 5123-5134. [CrossRef]

73. Canonici, A.; Gijsen, M.; Mullooly, M.; Bennett, R.; Bouguern, N.; Pedersen, K.; O’Brien, N.A.; Roxanis, I.; Li, J.L.; Bridge, E.; et al. Neratinib overcomes trastuzumab resistance in HER2 amplified breast cancer. Oncotarget 2013, 4, 1592-1605. [CrossRef]

74. Wen, W.; Chen, W.S.; Xiao, N.; Bender, R.; Ghazalpour, A.; Tan, Z.; Swensen, J.; Millis, S.Z.; Basu, G.; Gatalica, Z.; et al. Mutations in the kinase domain of the HER2/ERBB2 gene identified in a wide variety of human cancers. J. Mol. Diagn. 2015, 17, 487-495. [CrossRef]

75. Bose, R.; Kavuri, S.M.; Searleman, A.C.; Shen, W.; Shen, D.; Koboldt, D.C.; Monsey, J.; Goel, N.; Aronson, A.B.; Li, S.; et al. Activating HER2 mutations in HER2 gene amplification negative breast cancer. Cancer Discov. 2013, 3, 224-237. [CrossRef]

76. Zuo, W.J.; Jiang, Y.Z.; Wang, Y.J.; Xu, X.E.; Hu, X.; Liu, G.Y.; Wu, J.; Di, G.H.; Yu, K.D.; Shao, Z.M. Dual characteristics of novel HER2 kinase domain mutations in response to HER2-targeted therapies in human Breast Cancer. Clin. Cancer Res. 2016, 22, 4859-4869. [CrossRef]

77. Yang, B.; Zhang, H.; Wang, H. Atomistic insights into the lung cancer-associated L755P mutation in HER2 resistance to lapatinib: A molecular dynamics study. J. Mol. Model. 2015, 21, 24. [CrossRef] [PubMed]

78. Hanker, A.B.; Brewer, M.R.; Sheehan, J.H.; Koch, J.P.; Sliwoski, G.R.; Nagy, R.; Lanman, R.; Berger, M.F.; Hyman, D.M.; Solit, D.B.; et al. An acquired HER2(T798I) gatekeeper mutation induces resistance to neratinib in a patient with HER2 mutant-driven breast cancer. Cancer Discov. 2017, 7, 575-585. [CrossRef] [PubMed]

79. Arteaga, C.L.; Engelman, J.A. ERBB receptors: From oncogene discovery to basic science to mechanism-based cancer therapeutics. Cancer Cell 2014, 25, 282-303. [CrossRef] [PubMed]

80. Koga, T.; Kobayashi, Y.; Tomizawa, K.; Suda, K.; Kosaka, T.; Sesumi, Y.; Fujino, T.; Nishino, M.; Ohara, S.; Chiba, M.; et al. Activity of a novel HER2 inhibitor, poziotinib, for HER2 exon 20 mutations in lung cancer and mechanism of acquired resistance: An in vitro study. Lung Cancer 2018, 126, 72-79. [CrossRef] [PubMed]

81. Hyman, D.M.; Piha-Paul, S.A.; Won, H.; Rodon, J.; Saura, C.; Shapiro, G.I.; Juric, D.; Quinn, D.I.; Moreno, V.; Doger, B.; et al. HER kinase inhibition in patients with HER2- and HER3-mutant cancers. Nature 2018, 554, 189-194. [CrossRef] [PubMed]

82. Di Luca, A.; Henry, M.; Meleady, P.; O'Connor, R. Label-free LC-MS analysis of HER2+ breast cancer cell line response to HER2 inhibitor treatment. Daru 2015, 23, 40. [CrossRef] [PubMed] 
83. Avraham, R.; Yarden, Y. Feedback regulation of EGFR signalling: Decision making by early and delayed loops. Nat. Rev. Mol. Cell Biol. 2011, 12, 104-117. [CrossRef] [PubMed]

84. Hendriks, B.S.; Opresko, L.K.; Wiley, H.S.; Lauffenburger, D. Quantitative analysis of HER2-mediated effects on HER2 and epidermal growth factor receptor endocytosis: Distribution of homo- and heterodimers depends on relative HER2 levels. J. Biol. Chem. 2003, 278, 23343-23351. [CrossRef]

85. Baulida, J.; Kraus, M.H.; Alimandi, M.; Di Fiore, P.P.; Carpenter, G. All ErbB receptors other than the epidermal growth factor receptor are endocytosis impaired. J. Biol. Chem. 1996, 271, 5251-5257.

86. Sorkin, A.; Goh, L.K. Endocytosis and intracellular trafficking of ErbBs. Exp. Cell Res. 2008, 314, $3093-3106$. [CrossRef]

87. Marx, C.; Held, J.M.; Gibson, B.W.; Benz, C.C. ErbB2 trafficking and degradation associated with K48 and K63 polyubiquitination. Cancer Res. 2010, 70, 3709-3717. [CrossRef] [PubMed]

88. Pedersen, N.M.; Madshus, I.H.; Haslekas, C.; Stang, E. Geldanamycin-induced down-regulation of ErbB2 from the plasma membrane is clathrin dependent but proteasomal activity independent. Mol. Cancer Res. 2008, 6, 491-500. [CrossRef] [PubMed]

89. Xu, W.; Marcu, M.; Yuan, X.; Mimnaugh, E.; Patterson, C.; Neckers, L. Chaperone-dependent E3 ubiquitin ligase CHIP mediates a degradative pathway for c-ErbB2/Neu. Proc. Natl. Acad. Sci. USA 2002, 99, 12847-12852. [CrossRef] [PubMed]

90. Canonici, A.; Qadir, Z.; Conlon, N.T.; Collins, D.M.; O’Brien, N.A.; Walsh, N.; Eustace, A.J.; O’Donovan, N.; Crown, J. The HSP90 inhibitor NVP-AUY922 inhibits growth of HER2 positive and trastuzumab-resistant breast cancer cells. Investig. New Drugs 2018, 36, 581-589. [CrossRef] [PubMed]

91. Reif, R.; Adawy, A.; Vartak, N.; Schroder, J.; Gunther, G.; Ghallab, A.; Schmidt, M.; Schormann, W.; Hengstler, J.G. Activated ErbB3 translocates to the nucleus via clathrin-independent endocytosis, which is associated with proliferating cells. J. Biol. Chem. 2016, 291, 3837-3847. [CrossRef] [PubMed]

92. Collins, D.M.; Gately, K.; Hughes, C.; Edwards, C.; Davies, A.; Madden, S.F.; O’Byrne, K.J.; O’Donovan, N.; Crown, J. Tyrosine kinase inhibitors as modulators of trastuzumab-mediated antibody-dependent cell-mediated cytotoxicity in breast cancer cell lines. Cell. Immunol. 2017, 319, 35-42. [CrossRef]

93. Volpi, C.C.; Pietrantonio, F.; Gloghini, A.; Fuca, G.; Giordano, S.; Corso, S.; Pruneri, G.; Antista, M.; Cremolini, C.; Fasano, E.; et al. The landscape of d16HER2 splice variant expression across HER2-positive cancers. Sci. Rep. 2019, 9, 3545. [CrossRef] [PubMed]

94. Maruyama, T.; Mimura, K.; Izawa, S.; Inoue, A.; Shiba, S.; Watanabe, M.; Kawaguchi, Y.; Inoue, M.; Nogata, H.; Inoue, S.; et al. Lapatinib enhances herceptin-mediated antibody-dependent cellular cytotoxicity by up-regulation of cell surface HER2 expression. Anticancer Res. 2011, 31, 2999-3005.

95. Okita, R.; Shimizu, K.; Nojima, Y.; Yukawa, T.; Maeda, A.; Saisho, S.; Nakata, M. Lapatinib enhances trastuzumab-mediated antibody-dependent cellular cytotoxicity via upregulation of HER2 in malignant mesothelioma cells. Oncol. Rep. 2015, 34, 2864-2870. [CrossRef]

96. Shiraishi, K.; Mimura, K.; Izawa, S.; Inoue, A.; Shiba, S.; Maruyama, T.; Watanabe, M.; Kawaguchi, Y.; Inoue, M.; Fujii, H.; et al. Lapatinib acts on gastric cancer through both antiproliferative function and augmentation of trastuzumab-mediated antibody-dependent cellular cytotoxicity. Gastric Cancer 2013, 16, 571-580. [CrossRef]

97. Martinez, V.G.; O’Neill, S.; Salimu, J.; Breslin, S.; Clayton, A.; Crown, J.; O’Driscoll, L. Resistance to HER2-targeted anti-cancer drugs is associated with immune evasion in cancer cells and their derived extracellular vesicles. Oncoimmunology 2017, 6, e1362530. [CrossRef]

98. Gaynor, N.; Guibourdenche, M.; Browne, B.; O'driscoll, L.; O’brien, N.; O'donovan, N.; Crown, J.; Collins, D. Alterations to trastuzumab-induced antibody-dependent cell-mediated cytotoxicity (T-ADCC) in a lapatinib-resistant HER2+ breast cancer cell line model. Ann. Oncol. 2017, 28, mdx361.013. [CrossRef]

99. Codony-Servat, J.; Albanell, J.; Lopez-Talavera, J.C.; Arribas, J.; Baselga, J. Cleavage of the HER2 ectodomain is a pervanadate-activable process that is inhibited by the tissue inhibitor of metalloproteases- 1 in breast cancer cells. Cancer Res. 1999, 59, 1196-1201. [PubMed]

100. Moreno-Aspitia, A.; Hillman, D.W.; Dyar, S.H.; Tenner, K.S.; Gralow, J.; Kaufman, P.A.; Davidson, N.E.; Lafky, J.M.; Reinholz, M.M.; Lingle, W.L.; et al. Soluble human epidermal growth factor receptor 2 (HER2) levels in patients with HER2-positive breast cancer receiving chemotherapy with or without trastuzumab: Results from North Central Cancer Treatment Group adjuvant trial N9831. Cancer 2013, 119, 2675-2682. [CrossRef] [PubMed] 
101. Molina, M.A.; Codony-Servat, J.; Albanell, J.; Rojo, F.; Arribas, J.; Baselga, J. Trastuzumab (herceptin), a humanized anti-Her2 receptor monoclonal antibody, inhibits basal and activated Her2 ectodomain cleavage in breast cancer cells. Cancer Res. 2001, 61, 4744-4749. [PubMed]

102. Vazquez-Martin, A.; Oliveras-Ferraros, C.; Cufi, S.; Del Barco, S.; Martin-Castillo, B.; Menendez, J.A. Lapatinib, a dual HER1/HER2 tyrosine kinase inhibitor, augments basal cleavage of HER2 extracellular domain (ECD) to inhibit HER2-driven cancer cell growth. J. Cell. Physiol. 2011, 226, 52-57. [CrossRef]

103. Lee, C.K.; Davies, L.; Gebski, V.J.; Lord, S.J.; di Leo, A.; Johnston, S.; Geyer, C.; Cameron, D.; Press, M.F.; Ellis, C.; et al. Serum human epidermal growth factor 2 extracellular domain as a predictive biomarker for lapatinib treatment efficacy in patients with advanced breast cancer. J. Clin. Oncol. 2016, 34, 936-944. [CrossRef]

104. Eswarakumar, V.P.; Lax, I.; Schlessinger, J. Cellular signaling by fibroblast growth factor receptors. Cytokine Growth Factor Rev. 2005, 16, 139-149. [CrossRef]

105. Chia, K.H.; Fukuda, T.; Sofyantoro, F.; Matsuda, T.; Amai, T.; Shiozaki, K. Ragulator and GATOR1 complexes promote fission yeast growth by attenuating TOR complex 1 through Rag GTPases. eLife 2017, 6. [CrossRef]

106. Rani, S.; Corcoran, C.; Shiels, L.; Germano, S.; Breslin, S.; Madden, S.; McDermott, M.S.; Browne, B.C.; O'Donovan, N.; Crown, J.; et al. Neuromedin U: A candidate biomarker and therapeutic target to predict and overcome resistance to HER-tyrosine kinase inhibitors. Cancer Res. 2014, 74, 3821-3833. [CrossRef]

107. Xia, W.; Petricoin, E.F., 3rd; Zhao, S.; Liu, L.; Osada, T.; Cheng, Q.; Wulfkuhle, J.D.; Gwin, W.R.; Yang, X.; Gallagher, R.I.; et al. An heregulin-EGFR-HER3 autocrine signaling axis can mediate acquired lapatinib resistance in HER2+ breast cancer models. Breast Cancer Res. 2013, 15, R85. [CrossRef] [PubMed]

108. Canfield, K.; Li, J.; Wilkins, O.M.; Morrison, M.M.; Ung, M.; Wells, W.; Williams, C.R.; Liby, K.T.; Vullhorst, D.; Buonanno, A.; et al. Receptor tyrosine kinase ERBB4 mediates acquired resistance to ERBB2 inhibitors in breast cancer cells. Cell Cycle 2015, 14, 648-655. [CrossRef] [PubMed]

109. Ikink, G.J.; Hilkens, J. Insulin receptor substrate 4 (IRS4) is a constitutive active oncogenic driver collaborating with HER2 and causing therapeutic resistance. Mol. Cell. Oncol. 2017, 4, e1279722. [CrossRef] [PubMed]

110. Rexer, B.N.; Ham, A.J.; Rinehart, C.; Hill, S.; Granja-Ingram Nde, M.; Gonzalez-Angulo, A.M.; Mills, G.B.; Dave, B.; Chang, J.C.; Liebler, D.C.; et al. Phosphoproteomic mass spectrometry profiling links Src family kinases to escape from HER2 tyrosine kinase inhibition. Oncogene 2011, 30, 4163-4174. [CrossRef]

111. Eichhorn, P.J.; Gili, M.; Scaltriti, M.; Serra, V.; Guzman, M.; Nijkamp, W.; Beijersbergen, R.L.; Valero, V.; Seoane, J.; Bernards, R.; et al. Phosphatidylinositol 3-kinase hyperactivation results in lapatinib resistance that is reversed by the mTOR/phosphatidylinositol 3-kinase inhibitor NVP-BEZ235. Cancer Res. 2008, 68, 9221-9230. [CrossRef] [PubMed]

112. Li, Z.; Yang, S.S.; Yin, P.H.; Chang, T.; Shi, L.X.; Fang, L.; Fang, G.E. Activated estrogen receptor-mitogen-activated protein kinases cross talk confer acquired resistance to lapatinib. Thorac. Cancer 2015, 6, 695-703. [CrossRef]

113. McDermott, M.S.; Browne, B.C.; Conlon, N.T.; O’Brien, N.A.; Slamon, D.J.; Henry, M.; Meleady, P.; Clynes, M.; Dowling, P.; Crown, J.; et al. PP2A inhibition overcomes acquired resistance to HER2 targeted therapy. Mol. Cancer 2014, 13, 157. [CrossRef]

114. Oliveras-Ferraros, C.; Corominas-Faja, B.; Cufi, S.; Vazquez-Martin, A.; Martin-Castillo, B.; Iglesias, J.M.; Lopez-Bonet, E.; Martin, A.G.; Menendez, J.A. Epithelial-to-mesenchymal transition (EMT) confers primary resistance to trastuzumab (Herceptin). Cell Cycle 2012, 11, 4020-4032. [CrossRef]

115. Huang, C.; Park, C.C.; Hilsenbeck, S.G.; Ward, R.; Rimawi, M.F.; Wang, Y.C.; Shou, J.; Bissell, M.J.; Osborne, C.K.; Schiff, R. beta1 integrin mediates an alternative survival pathway in breast cancer cells resistant to lapatinib. Breast Cancer Res. 2011, 13, R84. [CrossRef]

116. Creedon, H.; Gomez-Cuadrado, L.; Tarnauskaite, Z.; Balla, J.; Canel, M.; MacLeod, K.G.; Serrels, B.; Fraser, C.; Unciti-Broceta, A.; Tracey, N.; et al. Identification of novel pathways linking epithelial-to-mesenchymal transition with resistance to HER2-targeted therapy. Oncotarget 2016, 7, 11539-11552. [CrossRef]

117. Lesniak, D.; Sabri, S.; Xu, Y.; Graham, K.; Bhatnagar, P.; Suresh, M.; Abdulkarim, B. Spontaneous epithelial-mesenchymal transition and resistance to HER-2-targeted therapies in HER-2-positive luminal breast cancer. PLoS ONE 2013, 8, e71987. [CrossRef] [PubMed]

118. Karakas, B.; Ozmay, Y.; Basaga, H.; Gul, O.; Kutuk, O. Distinct apoptotic blocks mediate resistance to panHER inhibitors in HER2+ breast cancer cells. Biochim. Biophys. Acta Mol. Cell Res. 2018, 1865, 1073-1087. [CrossRef] [PubMed] 
119. Zhao, M.; Scott, S.; Evans, K.; Yuca, E.; Murthy, R.; Avogadri-Connors, F.; Cutler, R.; Lalani, A.S.; Piha-Paul, S.; Meric-Bernstam, F. Exploring optimal targeted combination therapies with neratinib for HER2 ${ }^{+}$breast cancer. Cancer Res. 2017, 77, 4038. [CrossRef]

120. Chia, S.K.L.; Martin, M.; Holmes, F.A.; Ejlertsen, B.; Delaloge, S.; Moy, B.; Iwata, H.; von Minckwitz, G.; Mansi, J.; Barrios, C.H.; et al. PIK3CA alterations and benefit with neratinib: Analysis from the randomized, double-blind, placebo-controlled, phase III ExteNET trial. Breast Cancer Res. 2019, 21, 39. [CrossRef] [PubMed]

121. Sudhan, D.R.; Hanker, A.B.; Guerrero-Zotano, A.; Formisano, L.; Guo, Y.; Liu, Q.; Avogadri-Connors, F.; Cutler, R.E.; Lalani, A.S.; Bryce, A.; et al. Hyperactivation of mTORC1 drives acquired resistance to the pan HER tyrosine kinase inhibitor neratinib in HER2 mutant cancers [abstract]. In Proceedings of the American Association of Cancer Research Annual Meeting, Chicago, IL, USA, 14-18 April 2018. Abstract 1828.

122. Won, H.F.; Selcuklu, S.D.; Piha-Paul, S.A.; Saura, C.; Rodon, J.; Mayer, I.A.; Loi, S.; Shapiro, G.I.; Lu, J.; Brufsky, A.; et al. Paired tumor and cfDNA in patients with HER2-mutant solid tumors treated with neratinib reveals convergence of multiple on-target resistance mechanisms: Results from the SUMMIT "Basket" Trial. In Proceedings of the American Association of Cancer Research Annual Meeting, Atlanta, GA, USA, 29 March-3 April 2019.

123. Eckschlager, T.; Plch, J.; Stiborova, M.; Hrabeta, J. Histone deacetylase inhibitors as anticancer drugs. Int. J. Mol. Sci. 2017, 18, 1414. [CrossRef]

124. Lee, J.; Bartholomeusz, C.; Mansour, O.; Humphries, J.; Hortobagyi, G.N.; Ordentlich, P.; Ueno, N.T. A class I histone deacetylase inhibitor, entinostat, enhances lapatinib efficacy in HER2-overexpressing breast cancer cells through FOXO3-mediated Bim1 expression. Breast Cancer Res. Treat. 2014, 146, 259-272. [CrossRef]

125. Booth, L.; Roberts, J.L.; Poklepovic, A.; Avogadri-Connors, F.; Cutler, R.E.; Lalani, A.S.; Dent, P. HDAC inhibitors enhance neratinib activity and when combined enhance the actions of an anti-PD-1 immunomodulatory antibody in vivo. Oncotarget 2017, 8, 90262-90277. [CrossRef]

126. Booth, L.; Roberts, J.L.; Rais, R.; Cutler, R.E., Jr.; Diala, I.; Lalani, A.S.; Poklepovic, A.; Dent, P. Palbociclib augments neratinib killing of tumor cells that is further enhanced by HDAC inhibition. Cancer Biol. Ther. 2018, 20, 157-168. [CrossRef]

127. Gottesman, M.M.; Fojo, T.; Bates, S.E. Multidrug resistance in cancer: Role of ATP-dependent transporters. Nat. Rev. Cancer 2002, 2, 48-58. [CrossRef]

128. Dai, C.L.; Tiwari, A.K.; Wu, C.P.; Su, X.D.; Wang, S.R.; Liu, D.G.; Ashby, C.R., Jr.; Huang, Y.; Robey, R.W.; Liang, Y.J.; et al. Lapatinib (Tykerb, GW572016) reverses multidrug resistance in cancer cells by inhibiting the activity of ATP-binding cassette subfamily B member 1 and G member 2. Cancer Res. 2008, 68, 7905-7914. [CrossRef]

129. Dunne, G.; Breen, L.; Collins, D.M.; Roche, S.; Clynes, M.; O'Connor, R. Modulation of P-gp expression by lapatinib. Investig. New Drugs 2011, 29, 1284-1293. [CrossRef] [PubMed]

130. Collins, D.; Jacob, W.; Cejalvo, J.M.; Ceppi, M.; James, I.; Hasmann, M.; Crown, J.; Cervantes, A.; Weisser, M.; Bossenmaier, B. Direct estrogen receptor (ER)/HER family crosstalk mediating sensitivity to lumretuzumab and pertuzumab in ER+ breast cancer. PLoS ONE 2017, 12, e0177331. [CrossRef] [PubMed]

131. Wang, Y.C.; Morrison, G.; Gillihan, R.; Guo, J.; Ward, R.M.; Fu, X.; Botero, M.F.; Healy, N.A.; Hilsenbeck, S.G.; Phillips, G.L.; et al. Different mechanisms for resistance to trastuzumab versus lapatinib in HER2-positive breast cancers - role of estrogen receptor and HER2 reactivation. Breast Cancer Res. 2011, 13, R121. [CrossRef] [PubMed]

132. Sudhan, D.R.; Schwarz, L.J.; Guerrero-Zotano, A.; Formisano, L.; Nixon, M.J.; Croessmann, S.; Gonzalez Ericsson, P.I.; Sanders, M.; Balko, J.M.; Avogadri-Connors, F.; et al. Extended adjuvant therapy with neratinib plus fulvestrant blocks ER/HER2 crosstalk and maintains complete responses of ER(+)/HER2(+) breast cancers: Implications to the ExteNET trial. Clin. Cancer Res. 2019, 25, 771-783. [CrossRef] [PubMed]

133. Emde, A.; Mahlknecht, G.; Maslak, K.; Ribba, B.; Sela, M.; Possinger, K.; Yarden, Y. Simultaneous inhibition of estrogen receptor and the HER2 pathway in breast cancer: Effects of HER2 abundance. Transl. Oncol. 2011, 4, 293-300. [CrossRef] [PubMed]

134. Croessmann, S.; Formisano, L.; Kinch, L.N.; Gonzalez-Ericsson, P.I.; Sudhan, D.R.; Nagy, R.J.; Mathew, A.; Bernicker, E.H.; Cristofanilli, M.; He, J.; et al. Combined blockade of activating ERBB2 mutations and ER results in synthetic lethality of ER+/HER2 mutant breast cancer. Clin. Cancer Res. 2019, 25, 277-289. [CrossRef] [PubMed] 
135. Zhu, Y.; Sullivan, L.L.; Nair, S.S.; Williams, C.C.; Pandey, A.K.; Marrero, L.; Vadlamudi, R.K.; Jones, F.E. Coregulation of estrogen receptor by ERBB4/HER4 establishes a growth-promoting autocrine signal in breast tumor cells. Cancer Res. 2006, 66, 7991-7998. [CrossRef]

136. Fujiwara, S.; Hung, M.; Yamamoto-Ibusuk, C.M.; Yamamoto, Y.; Yamamoto, S.; Tomiguchi, M.; Takeshita, T.; Hayashi, M.; Sueta, A.; Iwase, H. The localization of HER4 intracellular domain and expression of its alternately-spliced isoforms have prognostic significance in ER+ HER2- breast cancer. Oncotarget 2014, 5, 3919-3930. [CrossRef]

137. Zhang, W.J.; Li, Y.; Wei, M.N.; Chen, Y.; Qiu, J.G.; Jiang, Q.W.; Yang, Y.; Zheng, D.W.; Qin, W.M.; Huang, J.R.; et al. Synergistic antitumor activity of regorafenib and lapatinib in preclinical models of human colorectal cancer. Cancer Lett. 2017, 386, 100-109. [CrossRef]

138. Booth, L.; Albers, T.; Roberts, J.L.; Tavallai, M.; Poklepovic, A.; Lebedyeva, I.O.; Dent, P. Multi-kinase inhibitors interact with sildenafil and ERBB1/2/4 inhibitors to kill tumor cells in vitro and in vivo. Oncotarget 2016, 7, 40398-40417. [CrossRef]

139. Booth, L.; Roberts, J.L.; Rais, R.; Cutler, R.E., Jr.; Diala, I.; Lalani, A.S.; Hancock, J.F.; Poklepovic, A.; Dent, P. Neratinib augments the lethality of [regorafenib + sildenafil]. J. Cell. Physiol. 2018. [CrossRef] [PubMed]

140. Saura, C.; Oliveira, M.; Feng., Y.-H.; Dai, M.-S.; Hurvitz, S.A.; Kim, S.-B.; Moy, B.; Delaloge, S.; Gradishar, W.J.; Masuda, N.; et al. Neratinib + capecitabine versus lapatinib + capecitabine in patients with HER2+ metastatic breast cancer previously treated with $\geq 2$ HER2-directed regimens: Findings from the multinational, randomized, phase III NALA trial. In Proceedings of the 2019 Annual Meeting American Society of Clinical Oncology, Chicago, IL, USA, 31 May-4 June 2019.

141. Hurvitz, S.; Chan, A.; Iannotti, N.; Ibrahim, E.; Chien, J.; Chan, N.; Kellum, A.; Hansen, V.; Marx, G.; Kendall, S.; et al. Abstract P3-14-01: Effects of adding budesonide or colestipol to loperamide prophylaxis on neratinib-associated diarrhea in patients with HER2+ early-stage breast cancer: The CONTROL trial. Cancer Res. 2018, 78, P3-14-01. [CrossRef]

(C) 2019 by the authors. Licensee MDPI, Basel, Switzerland. This article is an open access article distributed under the terms and conditions of the Creative Commons Attribution (CC BY) license (http://creativecommons.org/licenses/by/4.0/). 